\title{
Kernos
}

Revue internationale et pluridisciplinaire de religion grecque antique

$28 \mid 2015$

Varia

\section{Un règlement religieux de la région de Larissa}

cultes grecs et « orientaux »

Jean-Claude Decourt et A. Tziaphalias

\section{(2) OpenEdition}

1 Journals

\section{Édition électronique}

URL : http://journals.openedition.org/kernos/2321

DOI : $10.4000 /$ kernos. 2321

ISSN : 2034-7871

Éditeur

Centre international d'étude de la religion grecque antique

Édition imprimée

Date de publication : 1 octobre 2015

Pagination : 13-51

ISBN : 978-2-87562-055-2

ISSN : 0776-3824

\section{Référence électronique}

Jean-Claude Decourt et A. Tziaphalias, « Un règlement religieux de la région de Larissa », Kernos [En ligne], 28 | 2015, mis en ligne le 01 octobre 2017, consulté le 19 avril 2019. URL : http:// journals.openedition.org/kernos/2321 ; DOI : 10.4000/kernos.2321

Ce document a été généré automatiquement le 19 avril 2019

Kernos 


\section{Un règlement religieux de la région de Larissa}

Cultes grecs et « orientaux »

Jean-Claude Decourt et A. Tziaphalias

Cette inscription a fait l'objet d'une première présentation aux rencontres archéologiques de Volos en 2009: DECOURT, TZIAFALIAS (2012), p. 463-473, et de trois exposés, au séminaire de R. Parker à Oxford en mai 2014, au séminaire "Collection of Greek Ritual Norms » de l'Université de Liège en octobre de la même année, au séminaire d'épigraphie animé à Lyon par V. Chankowski en février 2015. Elle a surtout fait l'objet de discussions nombreuses au sein de l'équipe thessalienne de Lyon (R. Bouchon, L. Darmezin, B. Helly, G. Lucas, I. Pernin, E. Santin). Mes collègues des IGLS, J. Aliquot, P.-L. Gatier, J.-B. Yon, m'ont aidé à étayer certaines hypothèses et je dois aussi beaucoup aux amicales suggestions de G. Rougemont. Que tous en soient très sincèrement remerciés ici, mais il va de soi que les erreurs sont miennes.

\section{Introduction}

1 Ces trente dernières années, les recherches sur les cultes et les sanctuaires en Thessalie ont connu des développements significatifs, alors même que la région était restée longtemps en marge en ce domaine ${ }^{1}$. Cela tient d'abord aux découvertes archéologiques importantes qui y ont été faites. J'en citerai deux exemples majeurs. D'abord la découverte par B. Intzesiloglou d'un temple archaïque à Métropolis, en Thessalie occidentale, temple dans lequel a été mise au jour la statue de culte d'Apollon avec sa dédicace ${ }^{2}$. Ensuite les fouilles menées par A. Tziafalias à Pythoion de Perrhébie, où trois temples consacrés respectivement à Poséidon Patrôios, Apollon Dôréios et Artémis ont été découverts ${ }^{3}$. Les trouvailles et les études épigraphiques ont été aussi nombreuses. Le corpus de la cité d'Atrax, dans les IG, ne comptait qu'une petite poignée d'inscriptions : on connaît désormais une centaine de dédicaces ${ }^{4}$. Prospections et fouilles en Tripolis de Perrhébie ont également fourni une moisson abondante: une centaine de dédicaces à Pythoion, un nombre plus modeste à Dolichè et Azôros ${ }^{5}$. Tout cela a conduit à renouveler 
sensiblement l'image que nous avions des cultes thessaliens, cultes panhelléniques, cultes topiques, cultes « importés », culte impérial enfin 6 .

Le présent document, cependant, est exceptionnel dans la région. L'inscription est gravée sur une haute stèle de marbre blanc, légèrement pyramidante, couronnée d'un fronton triangulaire sur corniche à trois acrotères : le premier acrotère est presque complet, le deuxième détérioré et le troisième presque totalement détruit. Le corps de la stèle est pratiquement intact, malgré un petit éclat à un angle en bas et quelques éraflures sur la face B.

La pierre a été trouvée en 2002, mais son existence n'a été signalée que plusieurs années plus tard, peut-être du fait des conditions de sa découverte. Elle a en effet été signalée

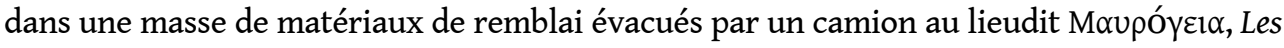

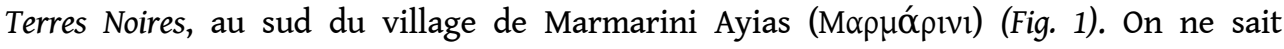
absolument pas d'où provient cette stèle, mais on ne peut s'empêcher de penser que, vu sa taille, son évacuation discrète n'est pas le fruit du hasard. Le monument est donc hors de tout contexte archéologique et le sanctuaire dont il est question ne se trouve pas sur le lieu de découverte. De surcroît, si des trouvailles préhistoriques ont été brièvement signalées dans le Deltion Archeologikon à Marmarini ${ }^{7}$, on ne connaît actuellement aucune trace d'époque historique dans le secteur.

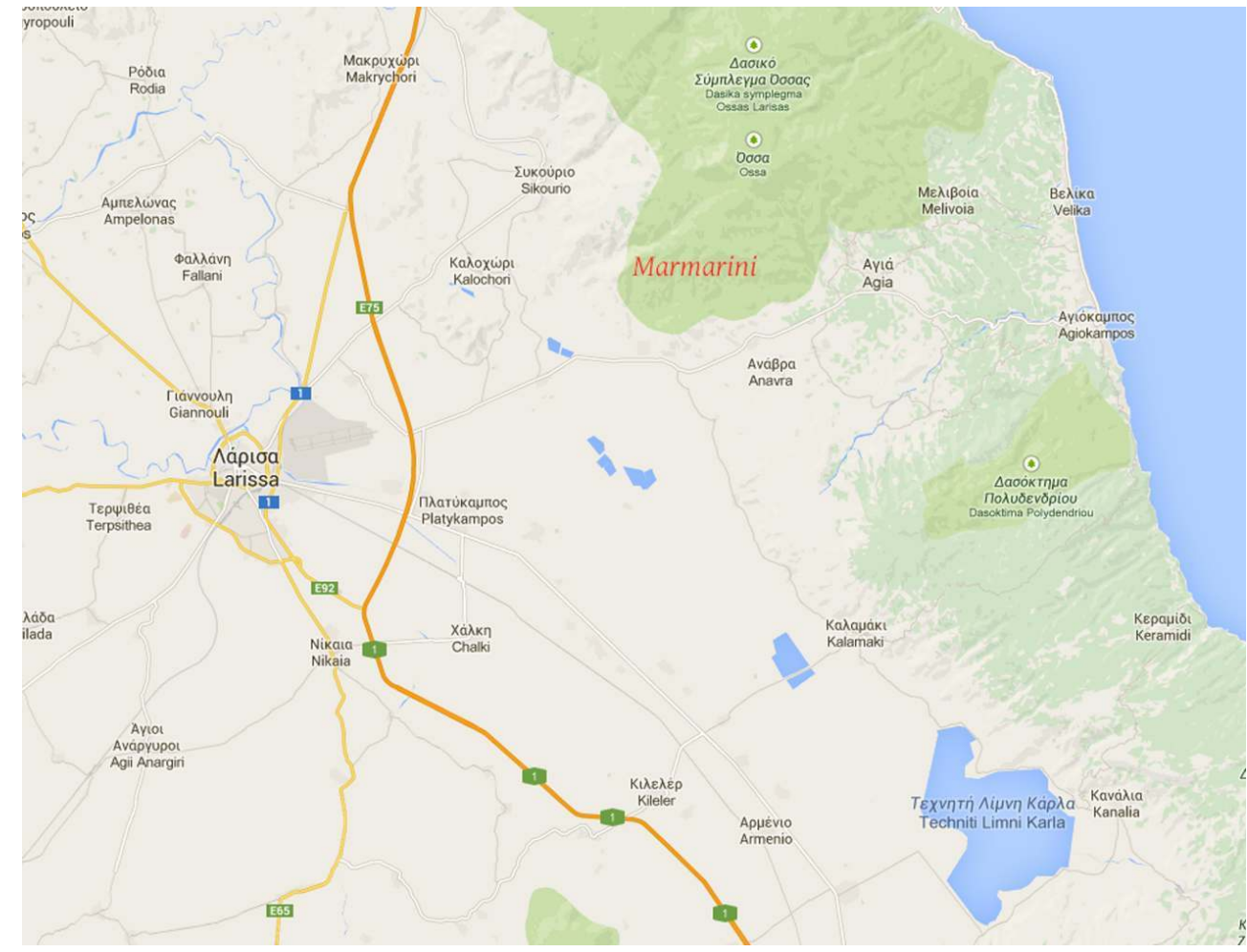

Fig. 1. Marmarini en Thessalie du nord-est

Source Google Map modifiée.

Dim. : $145 \times 48 / 42,5 \times 11,5 / 7,6$; h.l. : 0,4/0,5; int. : 0,3/0,5. Musée de Larissa, $\mathrm{n}^{\circ}$ inventaire $2002 / 33$. Base épigraphique de Lyon $n^{\circ}$ GHW05792. Estampages Lyon no 02858-60 ; 02865$66 ; 02947-48$.

Le monument est opisthographe. La gravure, peu profonde, est soignée et la dimension des lettres régulière ; subsistent, bien visibles sur la face $B$, les traces d'un réglage. La face appelée A dans l'inventaire compte actuellement cinquante-quatre lignes. Plus exposée 
aux intempéries, elle a beaucoup souffert, ce qui en rend la lecture très difficile et l'interprétation délicate. Les vingt et une premières lignes ont été totalement effacées et, vers la fin, les lignes 39-54 sont en très mauvais état de conservation. La face $B$, en revanche, malgré quelques lacunes, est conservée presque intégralement et compte quatre-vingt-deux lignes.

Graphie et datation. Apices peu marqués. Alpha à barre droite; epsilon à trois barres égales; $m u$ et $n u$ à hastes bien parallèles; sigma à barres légèrement divergentes ; $p i$ à hastes inégales; omicron un peu plus petit que les autres lettres et flottant sur la ligne ; thêta à point central; phi à haste dépassant nettement. Je proposerais donc de dater l'inscription du milieu du $\mathrm{II}^{\mathrm{e}}$ siècle av. J.-C. ${ }^{8}$.

\section{Texte face A (Fig. 2)}

\begin{tabular}{|c|c|}
\hline Manquent 21 lignes & \\
\hline 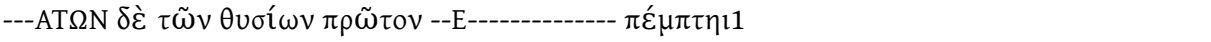 & \\
\hline 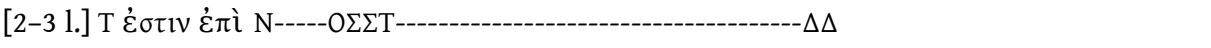 & \\
\hline 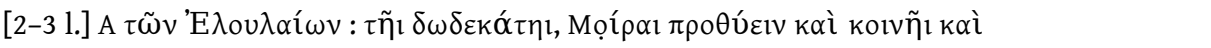 & \\
\hline 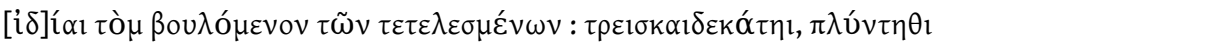 & 4 \\
\hline 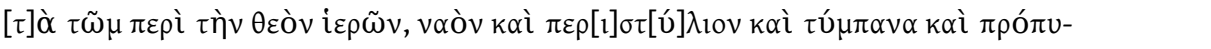 & \\
\hline 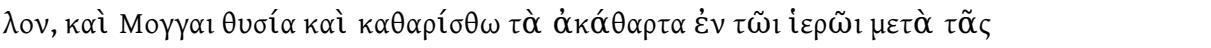 & \\
\hline 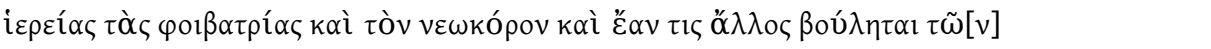 & \\
\hline 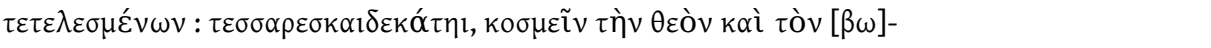 & 8 \\
\hline 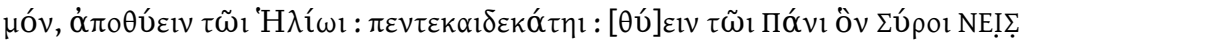 & \\
\hline 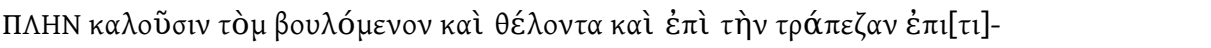 & \\
\hline 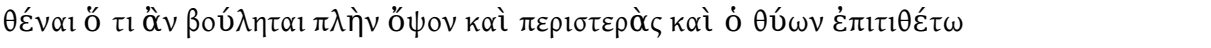 & \\
\hline 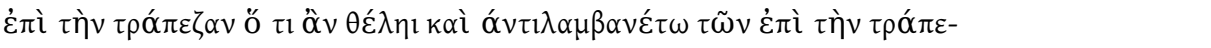 & 12 \\
\hline 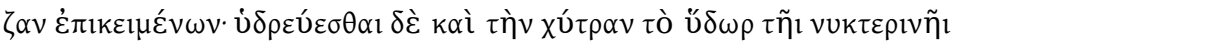 & \\
\hline 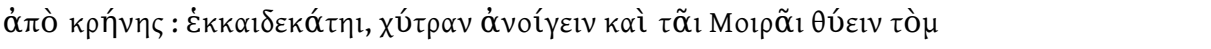 & \\
\hline 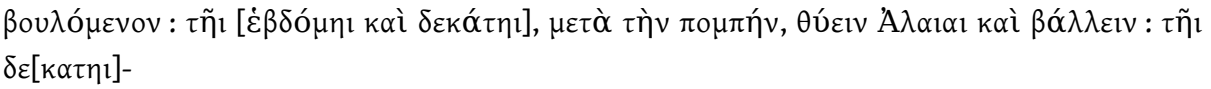 & \\
\hline 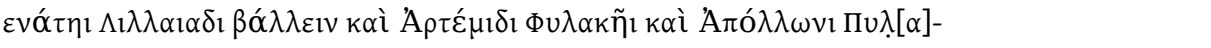 & 16 \\
\hline 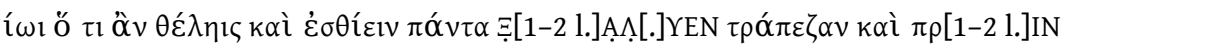 & \\
\hline 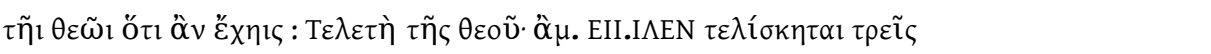 & \\
\hline
\end{tabular}




\begin{tabular}{|c|c|}
\hline \multicolumn{2}{|l|}{ 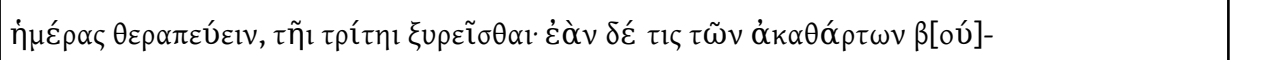 } \\
\hline 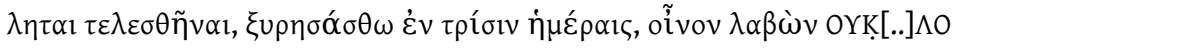 & 20 \\
\hline 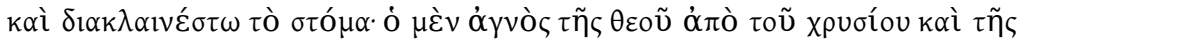 & \\
\hline 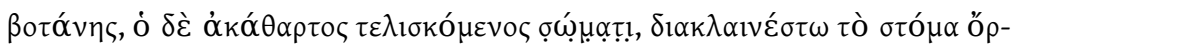 & \\
\hline 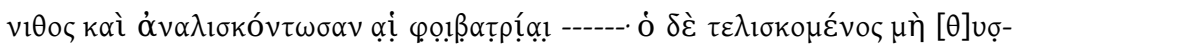 & \\
\hline 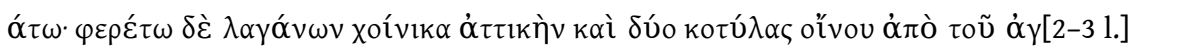 & 24 \\
\hline 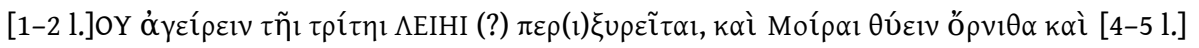 & \\
\hline 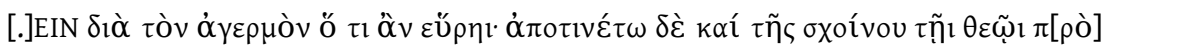 & \\
\hline 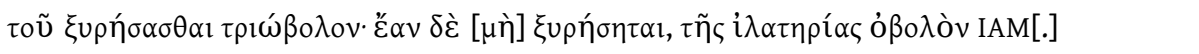 & \\
\hline 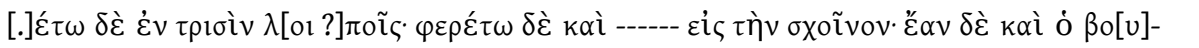 & 28 \\
\hline$\lambda$ & \\
\hline 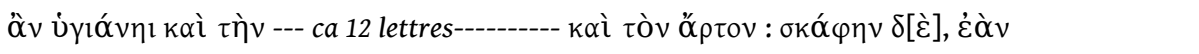 & \\
\hline 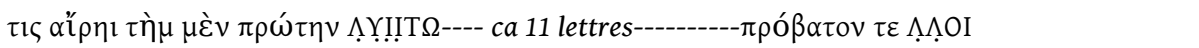 & \\
\hline 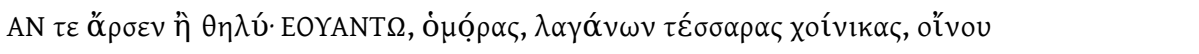 & 32 \\
\hline 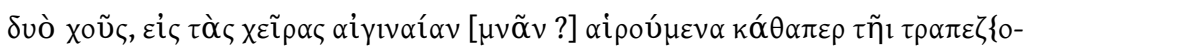 & \\
\hline 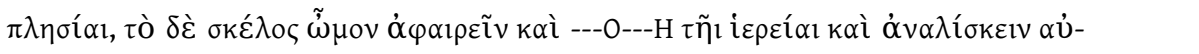 & \\
\hline 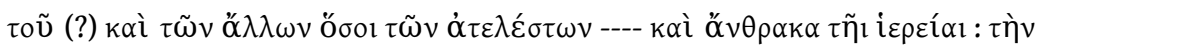 & \\
\hline 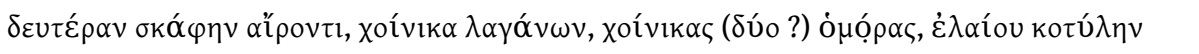 & 36 \\
\hline 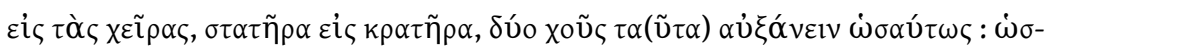 & \\
\hline 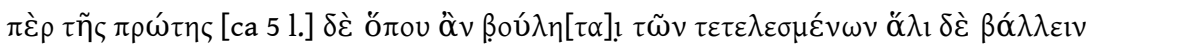 & \\
\hline 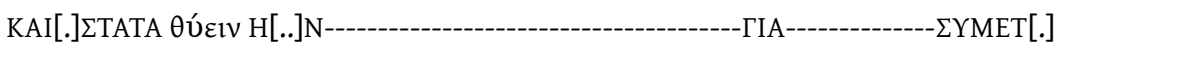 & \\
\hline [5-7 1.] TANZI[.] $\Lambda \mathrm{HI}---\mathrm{MH}----\mathrm{EN}----\Sigma \mathrm{I}---\mathrm{NOI} \Sigma \mathrm{I} \Sigma \Omega \mathrm{N}[.] \mathrm{N}---\mathrm{O} \Lambda . \mathrm{H}(?)$ & 40 \\
\hline 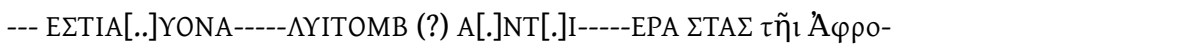 & \\
\hline 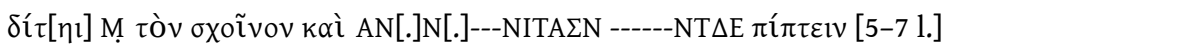 & \\
\hline 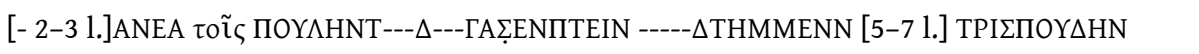 & \\
\hline 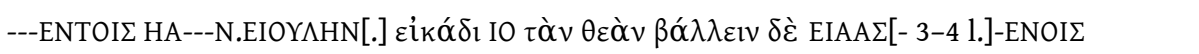 & 44 \\
\hline 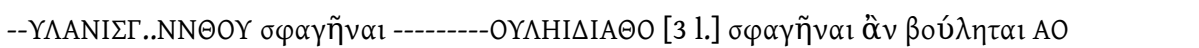 & \\
\hline
\end{tabular}




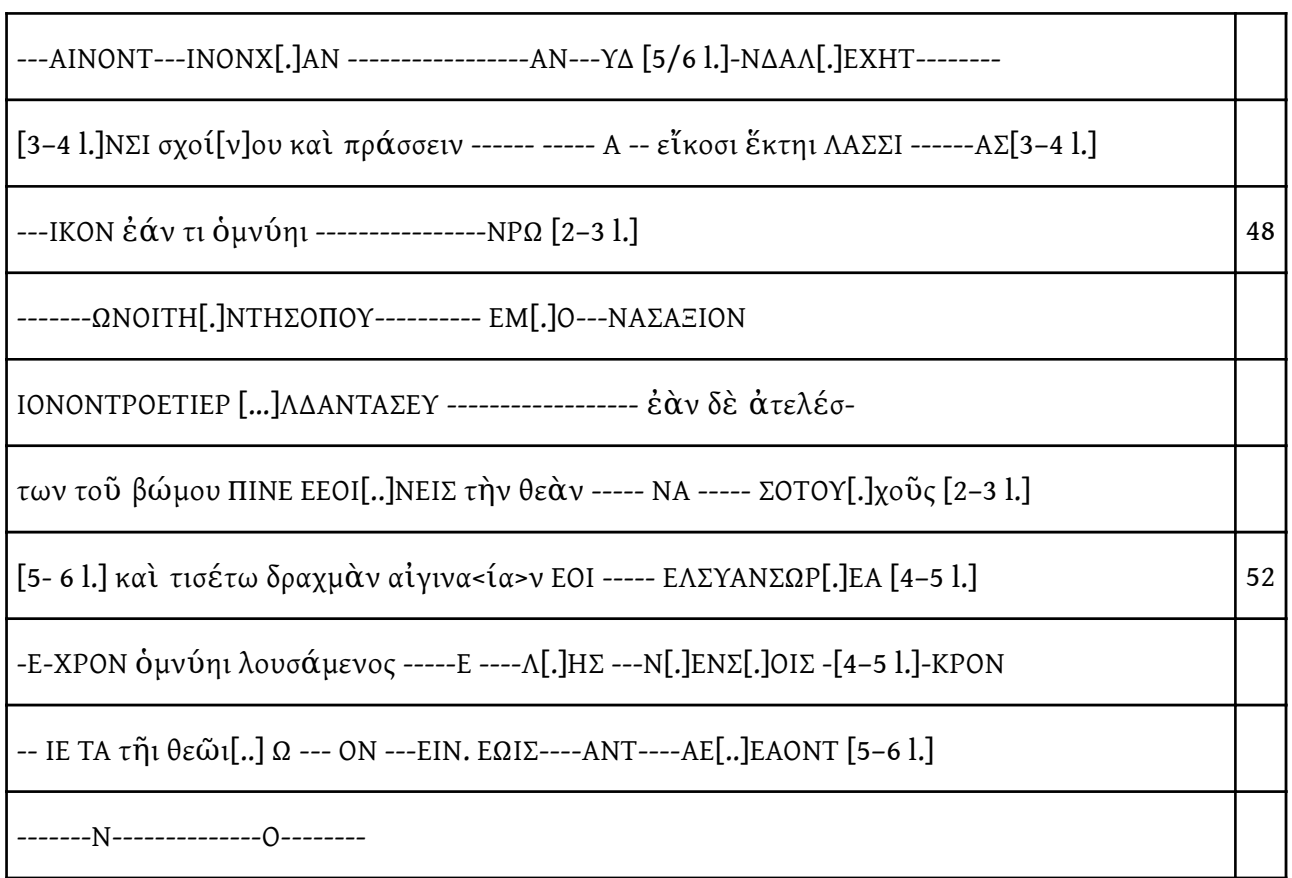

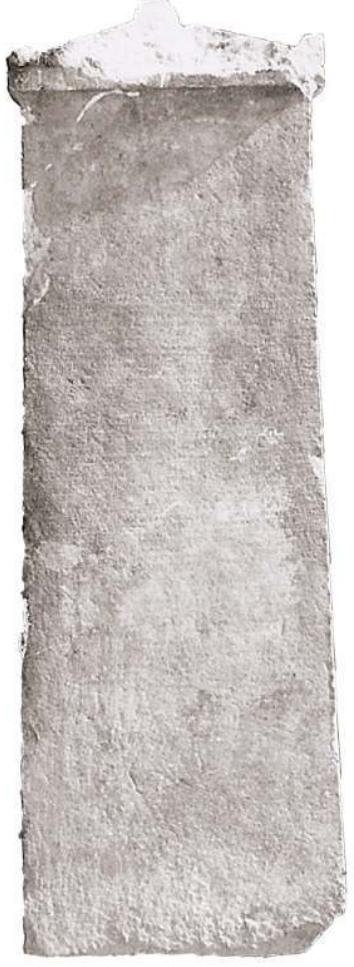

Fig. 2. Inscription de Marmarini, face A

Photo équipe thessalienne de Lyon.

\section{Texte face B (Fig. 3)}

\begin{tabular}{|c|}
\hline 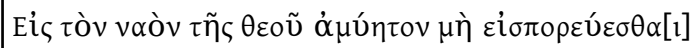 \\
\hline
\end{tabular}




\begin{tabular}{|c|c|}
\hline \multicolumn{2}{|l|}{ 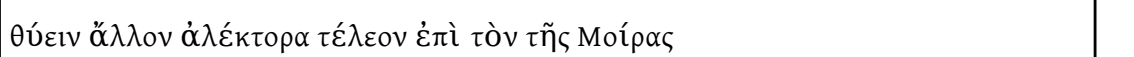 } \\
\hline 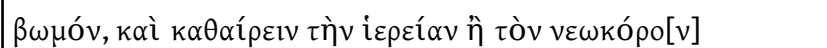 & 4 \\
\hline 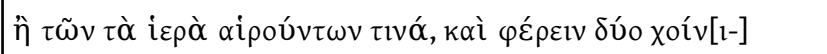 & \\
\hline 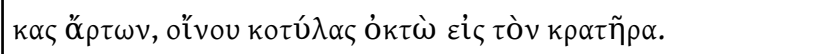 & \\
\hline 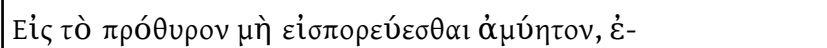 & \\
\hline 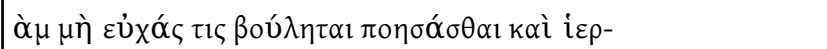 & 8 \\
\hline 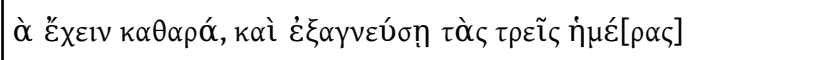 & \\
\hline 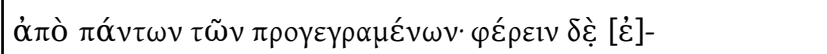 & \\
\hline 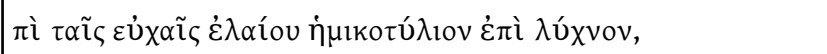 & \\
\hline 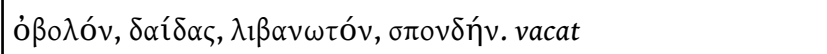 & 12 \\
\hline 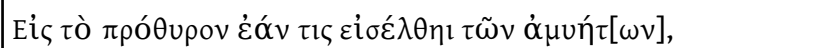 & \\
\hline 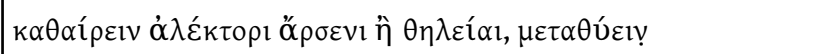 & \\
\hline 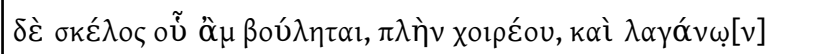 & \\
\hline 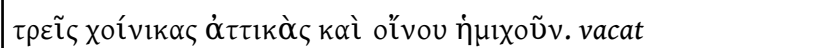 & 16 \\
\hline 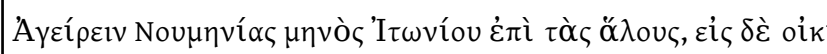 & \\
\hline 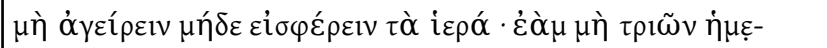 & \\
\hline 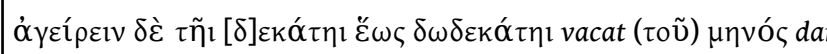 & \\
\hline 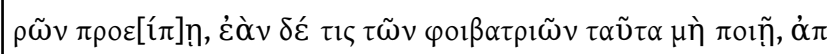 & 20 \\
\hline 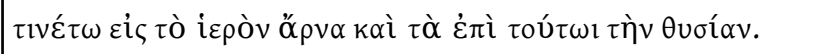 & \\
\hline 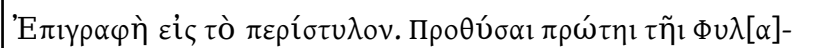 & \\
\hline 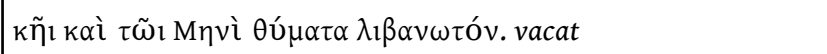 & \\
\hline 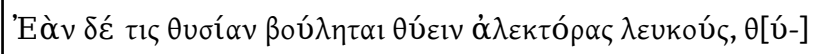 & 24 \\
\hline 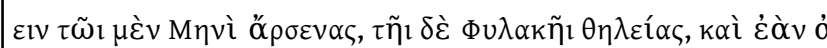 & \\
\hline 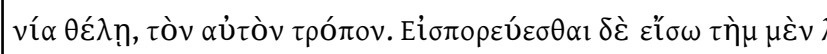 & \\
\hline 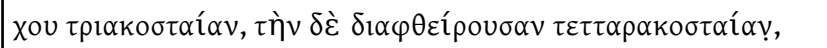 & \\
\hline 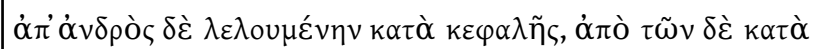 & 28 \\
\hline 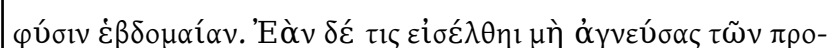 & \\
\hline
\end{tabular}




\begin{tabular}{|c|c|}
\hline \multicolumn{2}{|l|}{ 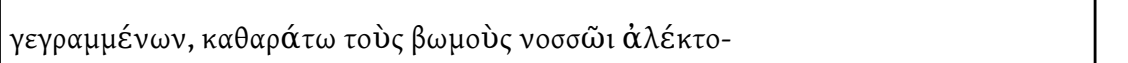 } \\
\hline 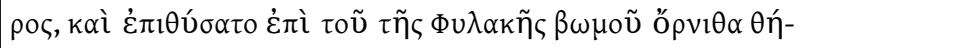 & \\
\hline 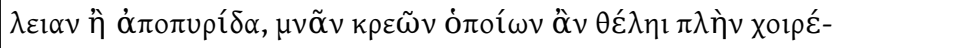 & 32 \\
\hline 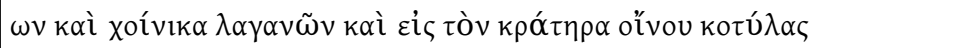 & \\
\hline 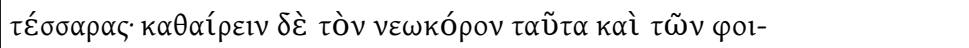 & \\
\hline 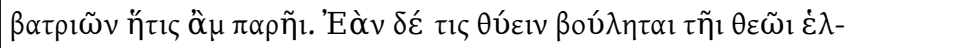 & \\
\hline 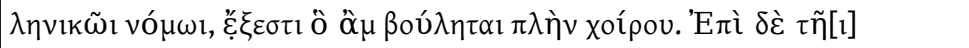 & 36 \\
\hline 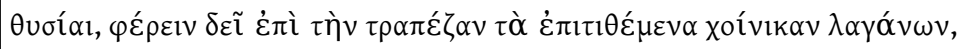 & \\
\hline 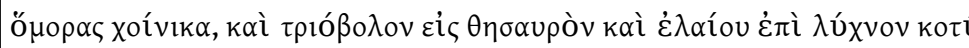 & \\
\hline 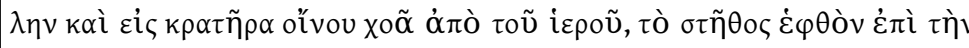 & \\
\hline 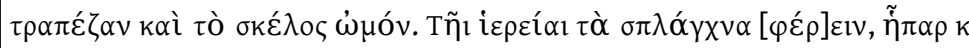 & 40 \\
\hline 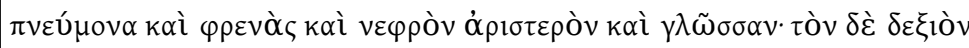 & \\
\hline 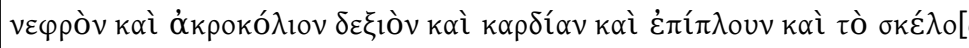 & \\
\hline 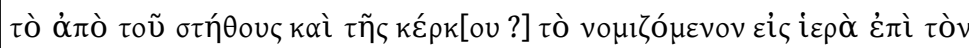 & \\
\hline 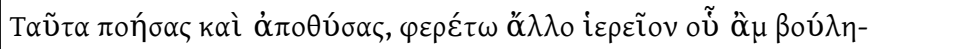 & 44 \\
\hline 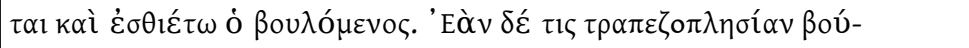 & \\
\hline 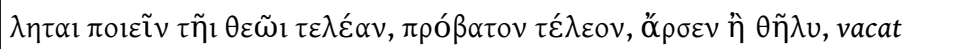 & \\
\hline 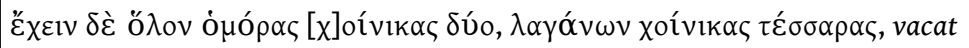 & \\
\hline 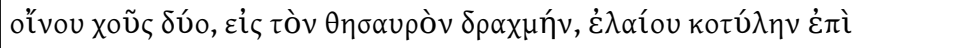 & 48 \\
\hline 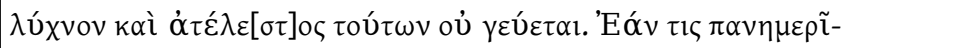 & \\
\hline 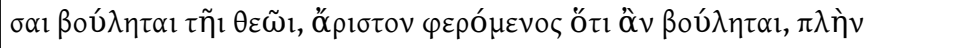 & \\
\hline 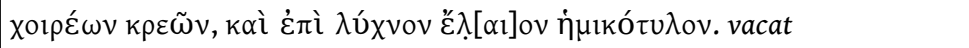 & \\
\hline 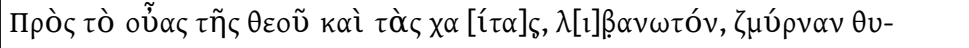 & 52 \\
\hline 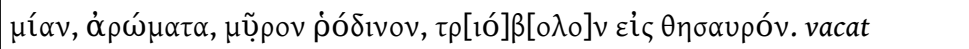 & \\
\hline 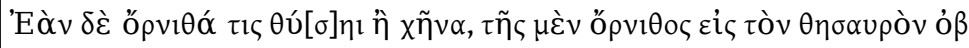 & \\
\hline 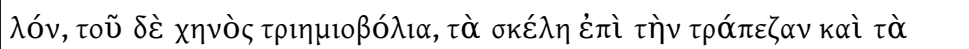 & \\
\hline 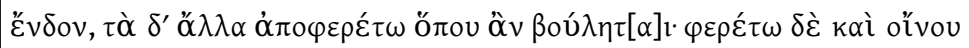 & 56 \\
\hline
\end{tabular}




\begin{tabular}{|c|c|}
\hline 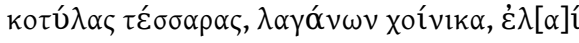 & \\
\hline 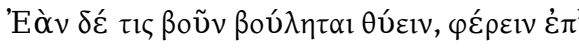 & \\
\hline 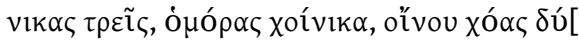 & \\
\hline 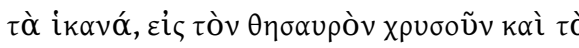 & 60 \\
\hline 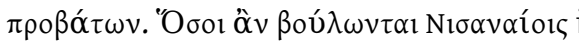 & \\
\hline 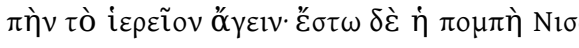 & \\
\hline 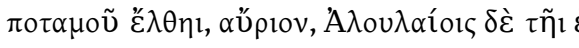 & \\
\hline 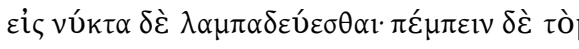 & 64 \\
\hline 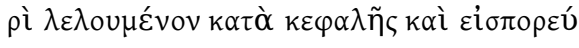 & \\
\hline 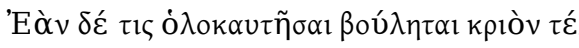 & \\
\hline 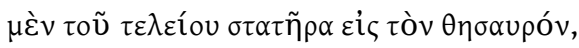 & \\
\hline 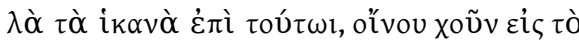 & 68 \\
\hline 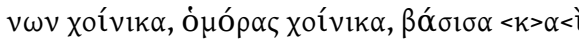 & \\
\hline 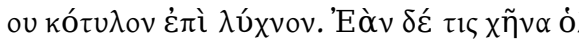 & \\
\hline 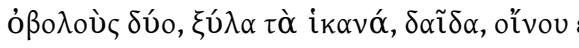 & \\
\hline 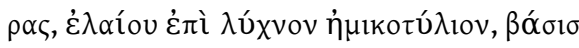 & 72 \\
\hline 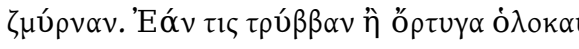 & \\
\hline 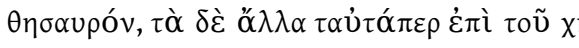 & \\
\hline 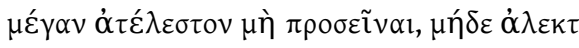 & \\
\hline 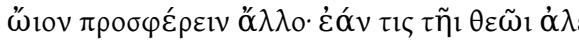 & 76 \\
\hline 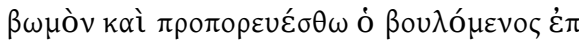 & \\
\hline 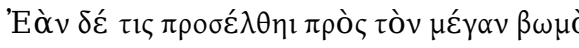 & \\
\hline 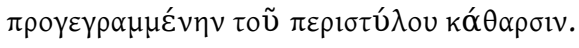 & \\
\hline 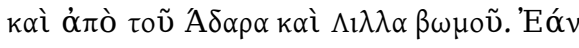 & 80 \\
\hline 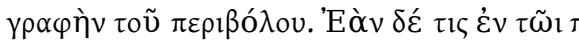 & \\
\hline 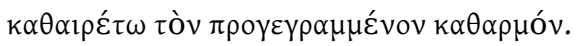 & \\
\hline
\end{tabular}




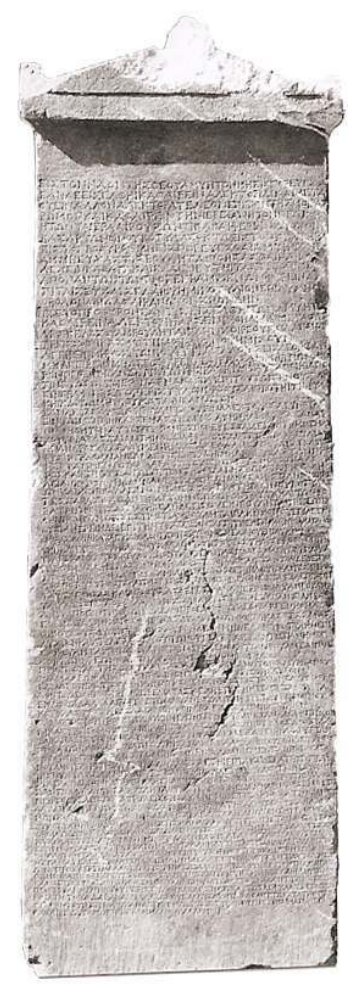

Fig. 3. Inscription de Marmarini, face B

Photo équipe thessalienne de Lyon.

\section{Traduction face A}

Manquent 21 lignes

des sacrifices, d'abord-

- Le cinq

des Éloulaia.

- Le 12. Qu'on fasse un sacrifice préliminaire à Moire, collectivement et, à titre privé, celui des initiés qui le veut.

4 - Le 13. Que soient lavés les bâtiments consacrés qui concernent la déesse, le temple, le péristyle, les vantaux (des portes) et la porte monumentale, et (que soit fait un) sacrifice à Mogga, que soit purifié ce qui est impur dans le sanctuaire, avec les purificatrices et le néocore et avec tout autre initié qui le souhaite.

8 - Le 14. Parer la déesse et l'autel; faire un sacrifice à Hélios.

- Le 15. Que sacrifie à Pan, que les Syriens appellent NEI $\Sigma \Pi \Lambda H N$, celui qui le veut et qui le désire ; qu'il mette sur la table ce qu'il veut, sauf du poisson et des colombes, et que celui qui fait le sacrifice place sur la table ce qu'il veut et $\mathbf{1 2}$ qu'il prenne en échange ce qui est déposé sur la table. Remplir d'eau la marmite d'eau puisée d'une fontaine, lors de la cérémonie nocturne.

- Le 16. Ouvrir la marmite et que qui le veut offre un sacrifice à Moire.

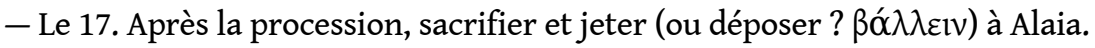

16 - Le 19. Jeter (ou déposer ? ßó $\lambda \lambda \varepsilon v$ ) à Lillaia, à Artémis Phylakè et à Apollon Pylaios ce qu'on veut et tout consommer --------- la table et --------- à la déesse ce qu'on a.

Cérémonie des mystères de la déesse. Si on doit procéder aux cérémonies d'initiation [e. 
g.], procéder au culte pendant trois jours, le troisième jour, se raser. Si l'un des impurs veut être 20 initié, qu'il soit rasé dans un délai de trois jours après avoir pris du vin ---- et qu'il garde bouche close (?). L'initié de la déesse, pur pour s'être abstenu [ou tenu à l'écart] de l'or et de l'herbe, celui qui est impur en cours d'initiation dans (?) son corps, qu'il brise le cou d'un oiseau (?) et que les purificatrices dépensent (?) ---- Que celui qui a été initié ne sacrifie pas, $\mathbf{2 4}$ mais qu'il apporte un chénice attique de beignets et deux cotyles de vin de la (vigne) consacrée, le troisième jour ---- il se rase complètement ; qu'il fasse la quête, et sacrifier à Moire un oiseau et ------- grâce à l'argent qu'il a tiré de la quête. Qu'il paie aussi pour la corbeille à la déesse avant d'être rasé, un triobole ; s'il n'est pas rasé, une obole d'offrande expiatoire ------- qu'il paie dans $\mathbf{2 8}$ les trois jours restants (?) ; qu'il apporte aussi --- pour la corbeille ; et si aussi celui qui veut procéder au culte (?) ---- par la déesse, qu'il procède au culte ---- s'il est en bonne santé et ------ et le pain, un bassin. Si quiconque le soulève le premier ------ du petit bétail 32 ------, mâle ou femelle. ----- bouillie au sésame, et quatre chénices de beignets, deux conges de vin, pour les mains une mine (?) éginète, des produits choisis comme pour la table pleine, séparer la patte non cuite et ---- pour la prêtresse et sur place (?) dépenser (?) --- et, parmi les autres, tous les non initiés ------ et du charbon pour la prêtresse. Pour qui soulève (?) le second bassin, un chénice de beignets, deux (?) chénices de bouillie au sésame, un cotyle d'huile pour les mains, un statère pour le cratère, deux conges

------ de même. --------- celui qui le veut des initiés, jeter avec du sel ?

\section{Traduction face B}

- Que, dans le temple de la déesse, aucun non-initié ne pénètre ; si un non-initié entre, accomplir la purification avec un coq et sacrifier ensuite un second coq adulte sur l'autel de Moire ; $\mathbf{4}$ et que procède à la purification soit la prêtresse, soit le néocore, soit l'un de ceux qui prennent les objets sacrés, et qu'ils apportent deux chénices de pain et huit cotyles de vin pour le cratère.

- Dans le vestibule, qu'aucun non-initié ne pénètre, 8 à moins de vouloir adresser des prières et conserver des hiéra purs et de se garder pur pendant les trois jours en se tenant à l'écart de toutes les souillures indiquées ci-dessus. Qu'il apporte pour les prières un demi cotyle d'huile pour la lampe, $\mathbf{1 2}$ une obole, des torches, de l'encens et de quoi faire une libation. Si l'un des non-initiés pénètre dans le vestibule, qu'on fasse la purification avec un coq ou une poule, qu'on offre ensuite une patte de l'animal de son choix, sauf d'un porc, trois $\mathbf{1 6}$ chénices attiques de beignets et un demi-conge de vin.

- Premier jour du mois Itônios : faire la quête sur les aires ; ne pas faire la quête dans une maison ni n'y introduire les objets sacrés; si on ne l'a pas annoncé trois jours d'avance, faire la quête du 10 au 12 du mois ; 20 si l'une des purificatrices ne fait pas cela, qu'elle paie comme amende au sanctuaire un mouton et le sacrifice pour.

Inscription sur le péristyle.

Qu'on fasse des offrandes en premier lieu à Phylakè et à Mên, des offrandes d'encens.

- 24 Si quelqu'un veut sacrifier des volailles blanches, qu'il sacrifie à Mên des mâles et à Phylakè des femelles, et s'il veut sacrifier de jeunes agneaux, qu'il agisse de la même façon.

- Pénétrer à l'intérieur du sanctuaire est autorisé à une accouchée au $30^{\circ}$ jour, à celle qui a avorté au $40^{\mathrm{e}}$ jour, 28 à celle qui a eu commerce avec un homme, après s'être lavée ensuite de la tête aux pieds, à celle qui s'est purifiée de ce qui se produit selon la nature au $7^{e}$ jour. Si on entre sans s'être gardé pur desdites impuretés, qu'on purifie les autels 
grâce à un poussin, et qu'on offre en outre sur l'autel de Phylakè une poule 32 ou un poisson apopyris, une mine de la viande qu'on veut, sauf de porc, et un chénice de beignet et pour le cratère quatre cotyles de vin. Qu'accomplissent ces purifications le néocore et celle des purificatrices qui se trouve présente.

- Si quelqu'un veut sacrifier à la déesse selon le rite $\mathbf{3 6}$ grec, c'est possible avec ce que l'on veut, sauf le porc. Pour ce sacrifice, il faut apporter ce que l'on met sur la table : un chénice de beignets, un chénice de bouillie au sésame, un triobole pour le tronc, un cotyle d'huile pour la lampe et, pour le cratère, un conge de vin provenant du sanctuaire. Déposer sur la table la poitrine cuite $\mathbf{4 0}$ et la patte crue; à la prêtresse remettre les entrailles, le foie, le poumon, les viscères, le rein gauche et la langue ; le rein droit, le pied (?) droit, le cœur, la membrane intestinale, la cuisse depuis la poitrine, et de la queue ce qui est d'usage, qu'on les apporte pour offrandes sacrées sur le feu. $\mathbf{4 4}$ Après avoir fait cela et après avoir fait la consécration, qu'on apporte une autre victime de l'espèce que l'on veut et qu'en mange qui veut.

- Si quelqu'un veut faire table pleine où rien ne manque pour la déesse, prendre un ovin adulte, mâle ou femelle. Prendre aussi, en tout, deux chénices de bouillie au sésame, quatre chénices de beignets, $\mathbf{4 8}$ deux conges de vin, une drachme pour le tronc, un cotyle d'huile pour la lampe et le non-initié n'en mange pas.

- Si quelqu'un veut consacrer toute une journée à la déesse, qu'il le fasse en apportant comme déjeuner ce qu'il veut, sauf de la viande de porc, et pour la lampe un demi-cotyle d'huile.

- 52 Pour l'oreille de la déesse et ses cheveux, de l'encens, de la myrrhe, des plantes aromatiques, de l'essence de rose, trois oboles pour le tronc.

- Si l'on sacrifie une volaille ou une oie, pour la volaille, qu'on verse au tronc 56 une obole, pour l'oie, une obole et demie, qu'on dépose les pattes et les viscères sur la table, le reste qu'on l'emporte où l'on veut; qu'on apporte aussi quatre cotyles de vin, un chénice de beignets et un demi cotyle d'huile.

- Si on veut sacrifier un bœuf, qu'on apporte sur la table trois chénices de $\mathbf{6 0}$ beignets, un chénice de bouillie au sésame, deux conges de vin, deux cotyles d'huile, du bois en suffisance, pour le tronc une pièce d'or et que l'on prélève les parts d'offrande comme dans le cas des ovins.

- Tous ceux qui veulent sacrifier lors des Nisanaia ou des Aloulaia, qu'ils conduisent la victime à la procession. Que la procession pour les Nisanaia se tienne quand la déesse arrive du fleuve, 64 le lendemain ; pour les Aloulaia, le 17 du mois au matin; à la tombée de la nuit, qu'on fasse une procession aux flambeaux ; que participe à la procession qui le veut, après qu'il s'est lavé le jour même de la tête au pied et qu'il lui soit permis d'aller jusque dans le sanctuaire de Phylakè.

- Si quelqu'un veut faire l'holocauste d'un bélier adulte ou, à défaut, d'un agneau mâle, 68 qu'il verse, pour le bélier, un statère au tronc et, pour l'agneau, une drachme éginétique, qu'il fournisse du bois en suffisance pour cela, un conge de vin pour le cratère, sur la table un chénice de bouillie au sésame, un chénice de beignets, de la rue des jardins et de la rue sauvage, de la myrrhe, un cotyle d'huile pour la lampe.

- Si quelqu'un veut faire l'holocauste d'une oie, qu'il verse au tronc $\mathbf{7 2}$ trois demi-oboles, qu'il fournisse du bois en suffisance, une torche, quatre cotyles de vin pour le cratère, un demi-cotyle d'huile pour la lampe, de la rue des jardins et de la rue sauvage, de l'encens de Smyrne.

- Si quelqu'un veut faire l'holocauste d'un oiseau trybba ou d'une caille, qu'il verse une obole et demie au tronc; pour le reste, tout comme pour l'oie. 
- Pour le grand autel, accès interdit au non-initié; pas de sacrifice de coqs; ne pas apporter un œuf de $\mathbf{7 6}$ n'importe quelle autre volaille, si l'on sacrifie à la déesse une poule sur l'autel de Moire ; et qu'accède qui le souhaite à l'autel de Moire et d'Hélios. Si un noninitié s'approche du grand autel, qu'on fasse la purification selon la procédure exposée précédemment pour la purification du péristyle.

- De même, qu'on se tienne aussi à l'écart de l'autel d'Adara et Lilla.

- 80 Si quelqu'un fait du feu, qu'on fasse la purification selon la prescription concernant le péribole; si quelqu'un, sous le péristyle, urine ou saigne, qu'on procède à la purification indiquée ci-dessus.

Ce document appartient à la catégorie bien connue des "règlements religieux », encore appelés « lois sacrées », deux expressions largement impropres on le sait, car on regroupe sous ces expressions des textes de natures très différentes. Si nos collègues de Liège ont entrepris à raison de trier et réviser cet ensemble disparate et de proposer un nouveau recueil, je conserverai l'expression consacrée encore pour un temps, pour les seuls besoins de la présente communication'.

Quoi qu'il en soit de la catégorie sous laquelle la ranger, l'inscription de Marmarini est tout à fait exceptionnelle pour la Thessalie. D'abord par sa longueur, puisqu'elle comptait, au total, probablement plus de 160 lignes. Ensuite et surtout par son contenu : mention de divinités nouvelles, prescriptions touchant à la pureté, allusion à un culte à mystères, liens avec l'Orient. Par sa rédaction enfin: je signalerai un certain nombre d'hapax significatifs.

7 Après avoir donné ci-dessus le texte et une traduction française, je proposerai une tentative de synthèse en m'intéressant successivement à l'archéologie du sanctuaire, aux divinités qui y sont présentes, aux modalités du culte - le personnel, les offrandes, la question de la pureté rituelle et surtout la question des mystères - avant de m'interroger sur l'autorité à l'origine de ce texte.

\section{Archéologie du sanctuaire}

8 Nous ignorons, du fait des conditions de découverte déjà signalées, l'emplacement du sanctuaire. En revanche, l'inscription permet de se faire une bonne idée de son aspect général, de son organisation interne sinon de son architecture. Disons d'emblée qu'il ne présente pas une originalité architecturale majeure par rapport à ce que nous connaissons.

9 Le sanctuaire est clos par une enceinte, $\pi \varepsilon \rho i ́ \beta 0 \lambda о \varsigma$ (B81), qui s'ouvre par une porte

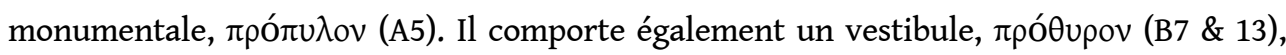
vestibule qui constitue une sorte de sas d'accès au sanctuaire proprement $\operatorname{dit}^{10} . \mathrm{Ce}$

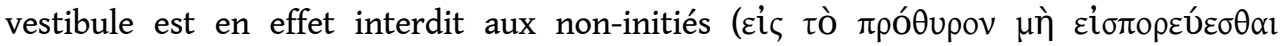

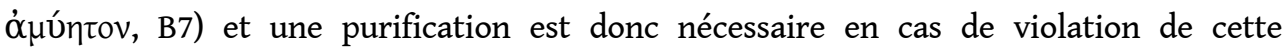

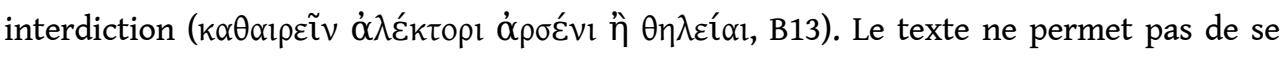
faire une idée précise de l'emplacement de ces deux éléments architecturaux, qui, mentionnés à deux endroits différents de l'inscription, ne paraissent du reste pas liés : le

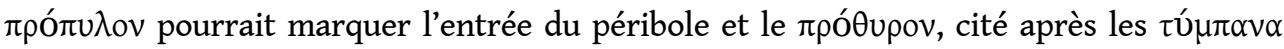
sur lesquels je reviendrai, l'entrée du temple.

10 Le bâtiment le plus important est le temple d'Artémis proprement dit, voó ৎ (A5, B1), qui abritait la statue de culte. Cette dernière n'est pas nommément citée, mais son existence 


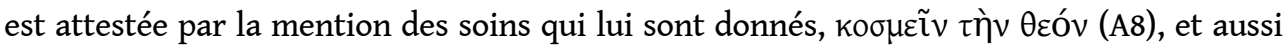
par la procession, $\dot{\eta} \pi 0 ́ \mu \pi \eta$, qui ramenait son image du fleuve au sanctuaire et dont on ne

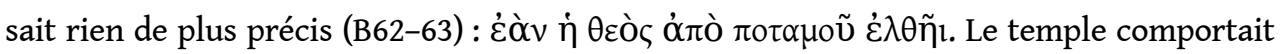

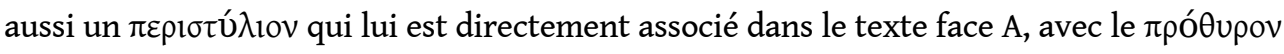

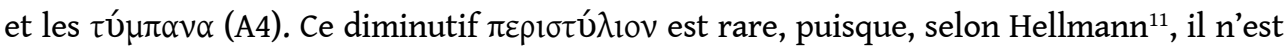
attesté ailleurs que deux fois, à Délos et à Sinope, où, dans ce dernier cas, il s'agit de surcroît d'une restitution ${ }^{12}$ : Hellmann ajoute qu' «il est difficile de dire en quoi le diminutif est justifié ». Quant au péristyle lui-même, $\pi \varepsilon p i ́ \sigma \tau u \lambda o v$, il apparaitt ailleurs dans le texte $(B 22,79,81)$ et désigne un élément architectural distinct, à l'intérieur du sanctuaire, mais qui n'est pas lié directement au temple d'Artémis : c'est en particulier le

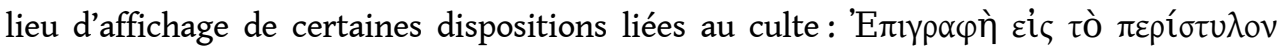
(B22).

11 On trouvait aussi dans le sanctuaire un certain nombre d'autels, $\beta \omega \mu$ ov́ $\varsigma$ (B30). On peut

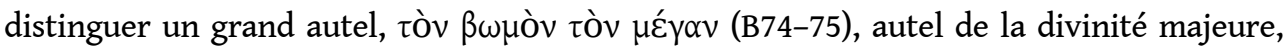

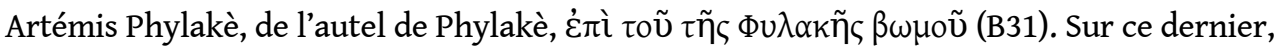
que je qualifierais volontiers de « secondaire » ou de « mineur », on peut en effet sacrifier

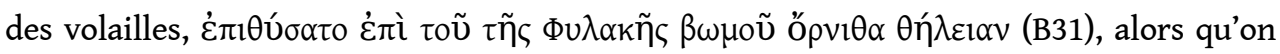

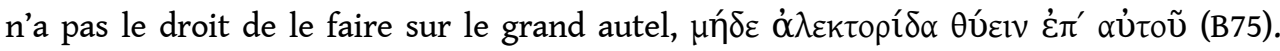

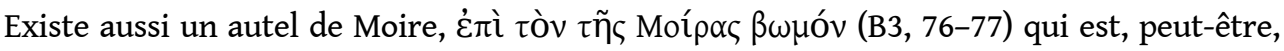

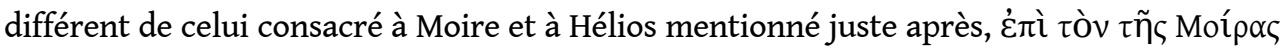

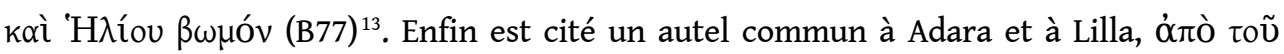

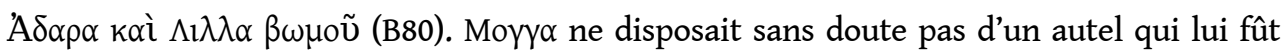

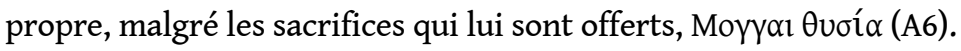

Le sanctuaire présentait également d'autres aménagements. D'abord une source aménagée (plutôt qu'une fontaine), où puiser l'eau nécessaire aux ablutions ou

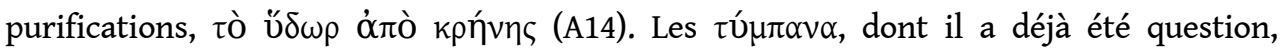

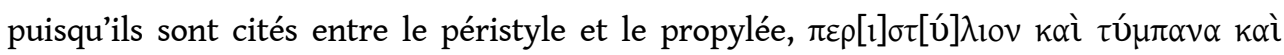

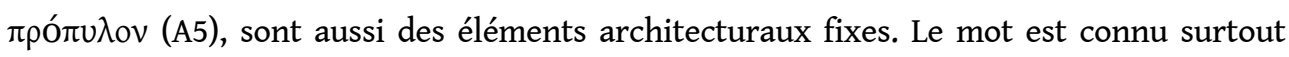
pour désigner un instrument de musique, divers éléments dans des constructions complexes comme les horloges à eau, enfin un instrument de torture. Tous ces sens ne conviennent évidemment pas. Dans le vocabulaire architectural, ce que nous appelons en

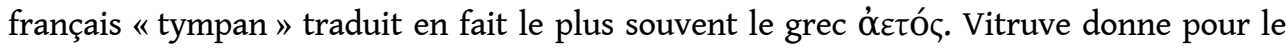

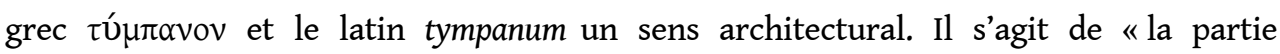
triangulaire du mur pignon qui ferme les combles dans un bâtiment dont le toit est à double pente». Mais ce sens ne convient pas non plus. Ainsi faut-il y voir, toujours d'après Vitruve, « le panneau mobile enserré dans le cadre d'une porte », la porte au sens courant du terme, ce que le français appelle aussi un « vantail », simple ou double comme c'est le cas ici pour une porte monumentale, la partie étant nommée pour le tout ${ }^{14}$. Il est en effet normal d'accorder une importance particulière à la propreté, à la pureté des portes d'accès au sanctuaire, qui séparent le vestibule du reste de la construction. Quant

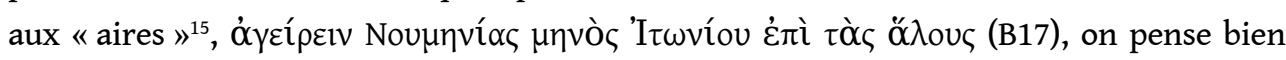
sûr à l'aire du sanctuaire d'Apollon à Delphes. Mais l'utilisation du pluriel dans l'inscription et le fait qu'il est difficile de savoir à coup sûr si ces structures étaient incluses à l'intérieur du péribole ou plutôt à chercher à l'extérieur de celui-ci, ainsi que le

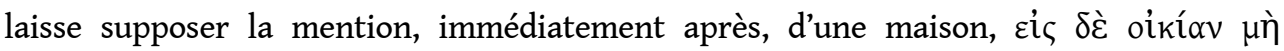

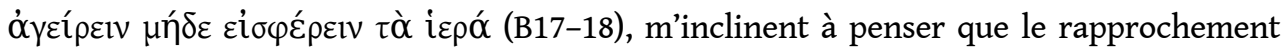


est discutable : on pense plutôt à de petites places, des piazzette, où le myste pouvait faire la quête, mais le sens serait nouveau.

En conclusion on soulignera simplement que se dessine un sanctuaire dont l'architecture ne se distingue somme toute en rien de la vulgate. Il n'en est pas tout à fait de même avec les divinités représentées.

\section{Les divinités}

\section{Artémis}

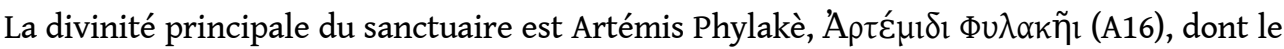
nom complet n'apparaît pourtant qu'une seule fois. Ailleurs et plus souvent, elle est

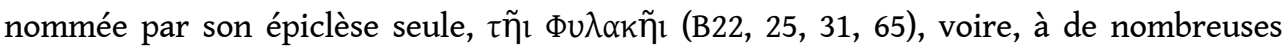
reprises, simplement $\dot{\eta} \theta \varepsilon$ ć $(\mathrm{A} 8,25,29$; B1, 35, 46, 50, 52, 62, 76). Ainsi la déesse apparaîtelle d'abord comme "La Gardienne » avant d'être Artémis et, du reste, la première fois qu'elle est nommée, c'est comme $\Phi \cup \lambda \alpha \kappa \eta ́$ (A8). Elle est la seule, en outre, dont le nom soit

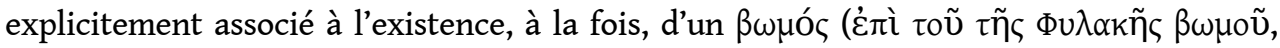

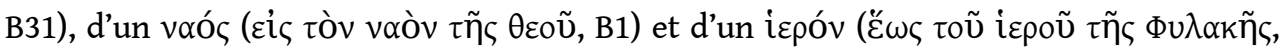
B65), ce qui en fait bien la divinité majeure et la titulaire du sanctuaire.

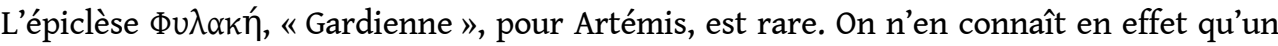
seul exemple épigraphique, sur une inscription d'Érétrie d'Eubée republiée naguère par D. Knoepfler ${ }^{16}$. Celui-ci a montré que, dans un règlement relatif aux concours des

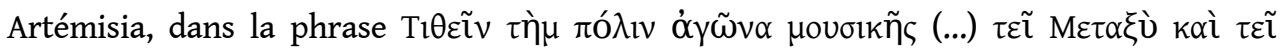

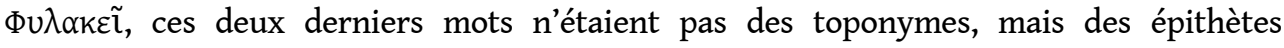
d'Artémis, qui avait été «neutre » et " protectrice » lors des troubles connus par la cité. Une scholie à Théocrite ${ }^{17}$ mentionne aussi pour Artémis l'épithète de $\Phi u ́ \lambda \alpha \xi$ ou, dans certains manuscrits, de $\Phi \cup \lambda \alpha \kappa \eta ́$, que le commentateur associe à celles de $\Delta \alpha \delta$ õ̃oৎ, $\Phi \omega \sigma \varphi$ ópoৎ et XӨovía, ce qui oriente vers une couleur du culte d'Artémis à la fois chthonienne et à mystères assez nette. De même, la notice d'Hésychius consacrée à

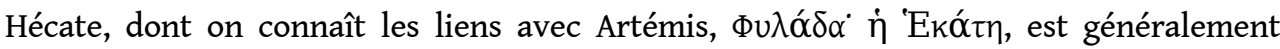
corrigée en $\Phi u \lambda \alpha^{\prime} \kappa \alpha^{18}$. Enfin, l'Anthologie Palatine la qualifie de « gardienne », dans un sens

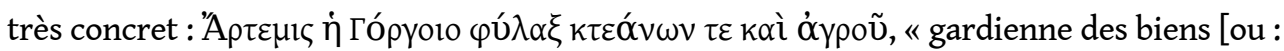
des troupeaux] et du domaine de Gorgos $»^{19}$.

On retrouve ce même adjectif pour un nombre limité de divinités. Asclépios est qualifié

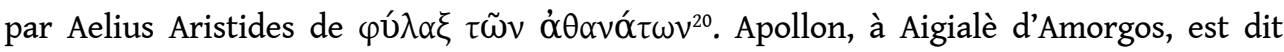

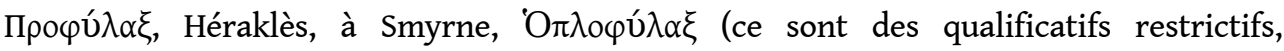

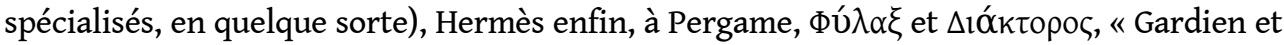
Messager ». Plus tardivement, on connaît à Rome une dédicace bilingue à Sylvain,

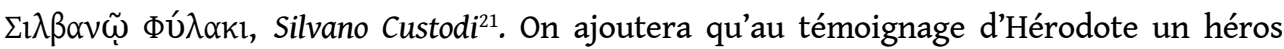
$\Phi u ́ \lambda \alpha \kappa o \zeta ~ a v a i t$ participé à la défense du sanctuaire de Delphes contre Xerxès : son hérôon se trouvait dans l'enceinte du sanctuaire d'Athéna ${ }^{22}$. Un homonyme, descendant d'Éole et aïeul de Jason, passait pour le fondateur de la cité thessalienne de Phylakè ${ }^{23}$. Mais surtout, toujours en Thessalie, Phylakè est l'une des épiclèses de Déméter, connue par plusieurs

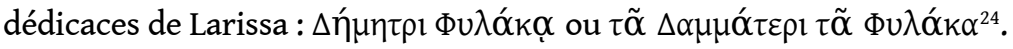


17 Pour terminer sur ce point, je rappellerai simplement que le caractère protecteur d'Artémis se manifeste par d'autres épithètes, beaucoup plus répandues, puisqu'elle est

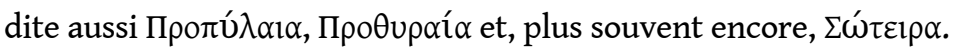

\section{Mên}

Artémis est associée, dans notre inscription, au dieu Mên ${ }^{25}$, lors d'un sacrifice qui paraît comporter deux étapes (B22-23 et 24-25) : un sacrifice préliminaire d'encens ( $\pi \rho 0 \theta \tilde{v} \sigma \alpha 1$

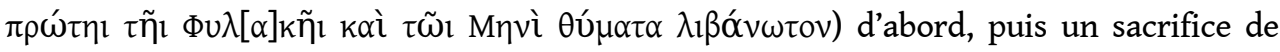
volailles blanches, coqs pour Mên, dont c'est du reste l'animal favori ${ }^{26}$, poules pour

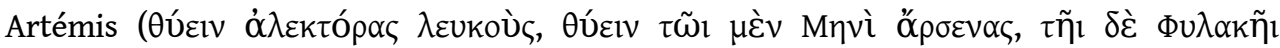

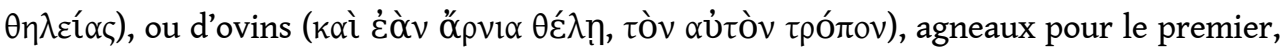
agnelles pour la seconde. Mên apparaît ainsi comme le parèdre d'Artémis, même si cette dernière occupe incontestablement la première place. Il n'a pas, dans notre texte, d'autel qui lui soit propre.

Si Mên est souvent, lui aussi, qualifié de $\Sigma \omega \tau \eta ́ p$, on connaît ailleurs d'autres exemples de son association avec Artémis qui s'explique, au moins en partie, par le caractère lunaire des deux divinités. Mên est associé à Artémis Éphésia sur une monnaie de Nysa de Lydie célébrant l'alliance entre cette cité et Éphèse au temps d'Élagabal ${ }^{27}$. En Lydie, à des dates

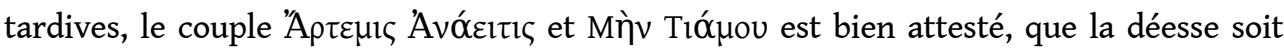
appelée Artémis Anaeitis, Anaeitis, la Grande Mère Anaeitis ou la Grande Artémis Anaeitis ${ }^{28}$. Nous sommes renvoyés ici à une Artémis que l'on pourrait qualifier d'orientale: Corsten $^{29}$ a bien montré que, depuis l'Iran pré-zoroastrien, le culte de la déesse Anahita, assimilée à Artémis, fut très tôt introduit en Asie Mineure. Hécate, à la fois déesse lunaire autonome et épiclèse d'Artémis enfin, est régulièrement associée à Mên en Asie Mineure ${ }^{30}$

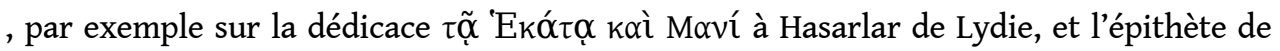
$\Phi \omega \sigma \varphi o_{0} \rho \zeta$ leur est commune ainsi qu'à Artémis, Mên étant parfois, en Lycaonie et Cilicie

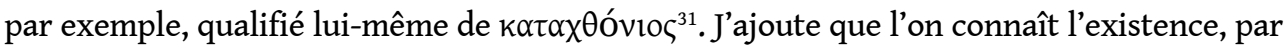
Pausanias et par Lucien, d'un culte initiatique à Hécate à Égine, institué, selon la légende, par Orphée, ce qui nous renvoie encore à l'une des figures d'Artémis ${ }^{32}$. En revanche, l'épithète d'Artémidoros qualifiant Mên, connue par plusieurs dédicaces, fait encore discussion. Le qualificatif renvoie, selon l'interprétation généralement admise, au nom du fondateur du culte ou du constructeur du sanctuaire, mais certains chercheurs font l'hypothèse que, pour les fidèles d'époque impériale au moins, cette référence aux origines était perdue et que le terme avait pris valeur d'épiclèse associant étroitement, voire subordonnant Mên à Artémis ${ }^{33}$.

L'introduction du culte de Mên en Grèce paraît s'être faite par l'intermédiaire de commerçants et d'esclaves. Les témoignages sont cependant peu nombreux : dans son catalogue, Lane en connaissait seulement dix-sept en 1971 pour la Grèce (Attique et Delphes) et les îles (Eubée, Délos, Thasos), auxquelles on peut ajouter deux documents rhodiens, inscriptions et reliefs anépigraphes confondus. Très peu de découvertes ont été faites depuis. Les plus anciens documents proviennent d'Attique et datent de la seconde

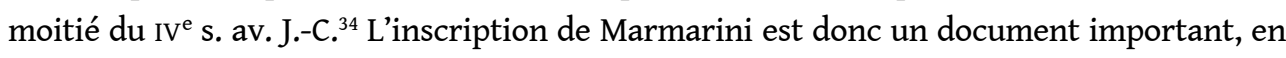
ce qu'il montre la présence du culte de Mên dans une région, la Thessalie, où il n'était pas encore attesté. Le contexte dans lequel son nom apparaît sur l'inscription permet de le rapprocher de deux témoignages plus tardifs. L'une des trois dédicaces à Mên Tyrannos de Sounion, datée du $\mathrm{I}^{\mathrm{er}} \mathrm{s}$. ap. J.-C., en effet, est suivie d'un très court règlement religieux, 
et, à Rhodes, deux stèles funéraires d'époque impériale sont érigées par une communauté

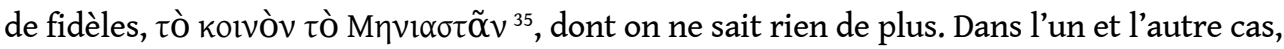
on a la preuve que nous sommes bien en présence d'un culte organisé et collectif et non d'une simple dévotion individuelle ${ }^{36}$.

\section{Moire}

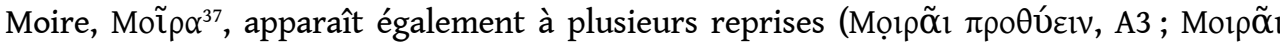

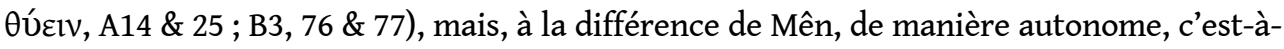
dire sans être associée à Artémis. Elle dispose du reste d'un autel qui lui est propre (غ่đì

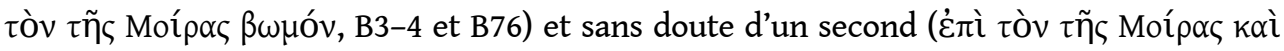
'H入íov $\beta \omega \mu$ óv, B77) qu'elle partage avec Hélios. Cette dernière association permet de mettre en valeur l'une des deux faces de la nature de cette divinité mineure, face solaire et olympienne ${ }^{38}$, la plupart du temps négligée au profit de son volet funéraire et chthonien.

On notera d'abord que, dans cette inscription, le nom de la divinité est au singulier, ce qui est beaucoup moins fréquent qu'au pluriel ${ }^{39}$. Ensuite et si l'on met de côté les innombrables mentions funéraires, en particulier dans les épigrammes, le culte de la ou des Moires n'est pas très répandu : on en compte seulement une douzaine d'attestations.

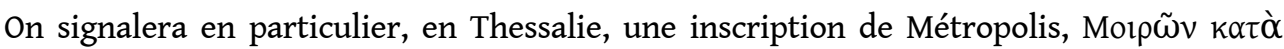

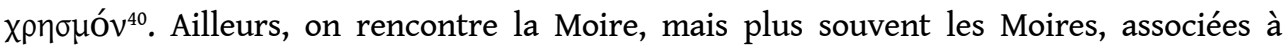
plusieurs reprises avec Artémis ${ }^{41}$. C'est le cas notamment à Sparte avec Artémis Orthia, où

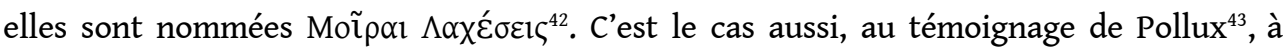
Athènes, où elles sont destinataires, avec Héra Téléia, de sacrifices prénuptiaux. Moire est associée avec Hécate sur des défixions d'Athènes ${ }^{44}$, en même temps que Corè, Perséphone et les Érinyes: c'est, dans ce cas, la face chthonienne et funéraire de la divinité qui est mise en valeur.

\section{Autres divinités du panthéon grec}

Plusieurs autres divinités sont simplement mentionnées dans l'inscription. Outre Hélios,

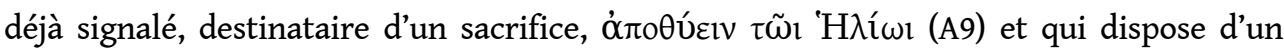

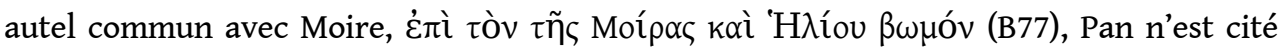

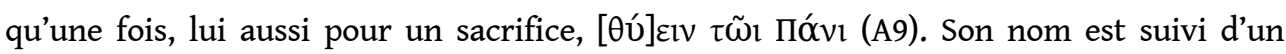

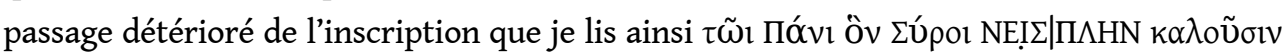
${ }^{45}$ : l'épithète ne se laisse malheureusement pas déchiffrer et on peut se demander quelle divinité se cache derrière ces lettres ${ }^{46}$. Il est question aussi d'Apollon (A16), associé à Artémis Phylakè : le texte se laisse lire difficilement, mais l'épithète est sans doute

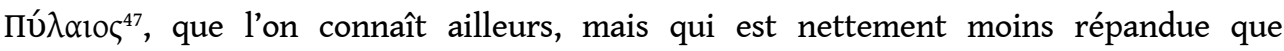

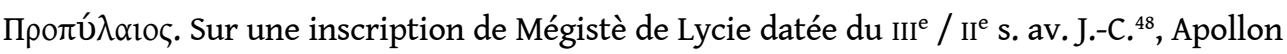
est, avec cette épiclèse, associé à Artémis Sôteira. En Thessalie, c'est Poséidon qui est qualifié de Pylaios, sur une inscription de Larissa ${ }^{49}$. Enfin, si mon déchiffrement, une fois encore, est bien exact, il est également fait mention (A41-42) de la déesse Aphrodite, $\tau \tilde{\eta} 1$ A $\varphi \rho \circ \mid \delta i ́ \tau[\eta 1]$ : je serai cependant très prudent, car toute cette section de l'inscription est en très mauvais état. 


\section{Autres divinités}

Moryal $\theta v \sigma i \alpha$; en A15 et A16, sont ordonnés des sacrifices et une autre action, que je ne

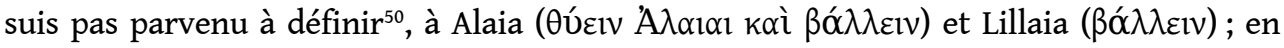

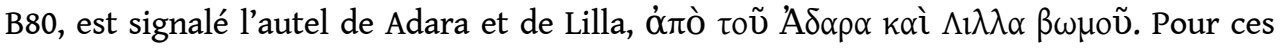
deux divinités, on peut s'interroger pour savoir s'il s'agit de dieux - ce à quoi conduit la forme normale du génitif - ou de déesses - ce qui signifierait que les noms ne sont pas déclinés, au contraire de ceux des deux premiers. Quoi qu'il en soit, il semble que nous soyons en présence de deux paires, Alaia / Lillaia d'un côté et Adara / Lilla de l'autre, de même que semblent être appariés, quoique moins nettement, Artémis et Mên, Moire et Hélios. Ces divinités ne sont pas grecques et le texte même du règlement laisse entrevoir l'existence d'influences étrangères fortes sur le déroulement du culte, mais aussi, évidemment, sur l'identité des divinités elles-mêmes. En B35-36, on lit en effet la

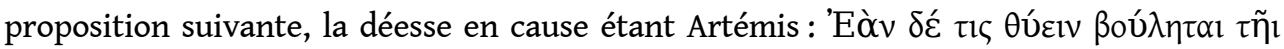
$\theta \varepsilon \omega \tilde{\omega} l \dot{\varepsilon} \lambda \mid \lambda \eta v ı \kappa \tilde{l}$ vó $\mu \omega$ l. La possibilité de sacrifier à Phylakè selon le « rite grec » implique qu'il pouvait (ou devait), dans le même sanctuaire, en être pratiqué un autre, dont l'origine n'est pas explicitée dans ce que nous lisons. On connaît, par Pausanias ${ }^{51}$, une formule sinon identique tout au moins très proche. Lorsque Phrixos sacrifie à Zeus Laphystios le bélier sur le dos duquel il est arrivé en Colchide, il découpe les cuisses

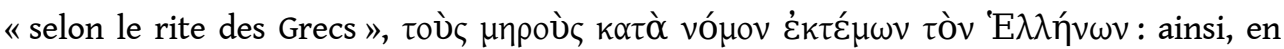
pays barbare, le sacrificateur affiche-t-il clairement sa qualité de Grec. Dans notre inscription, la situation est inversée pourrait-on dire, puisque nous sommes en Grèce, dans le cadre d'un culte importés2. Néanmoins, il faut bien voir que presque toutes les pratiques évoquées dans le présent règlement peuvent parfaitement s'insérer dans un rituel grec. On ne sait donc rien sur cet "autre rite», ce rite "non grec», sauf son existence.

Peut-on envisager que ces pratiques, que l'on pourrait qualifier d'exotiques, étaient décrites sur une autre stèle? Nous n'avons aucun argument pour appuyer cette hypothèse. La coloration orientale du culte est certes perceptible dans le nom des deux

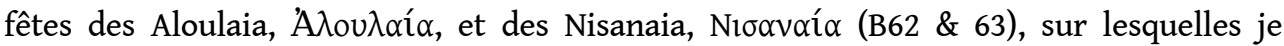
reviens plus loin. Mais il faut insister sur le fait que ces deux fêtes s'insèrent clairement dans le culte principal, celui d'Artémis Phylakè, et que, si l'on met à part leur nom, leur déroulement, ou ce que nous en percevons (procession diurne et procession aux flambeaux, bain rituel), elles n'ont rien de particulièrement original. De surcroît elles ne nous disent rien à propos des cinq divinités «étrangères ». Quant à l'exclusion du porc,

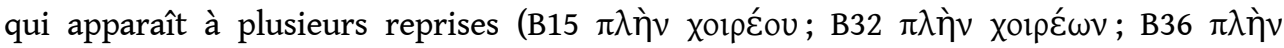
xoípov), on sait bien qu'elle ne permet pas, à elle seule, de parler de culte oriental ${ }^{53}$; du reste cette exclusion (B36) concerne explicitement le culte d'Artémis.

Les noms résistent à l'interprétation. C'est le cas pour Lilla et Allaia, pour lesquels je n'ai trouvé aucune correspondance. Le mot Moggas apparaît chez Athénée, mais c'est un hapax : c'est, pour lui, le nom d'une danse sauvage dont il ne nous dit pas dans quelle 
région elle était pratiquée et dont on n'est même pas assuré qu'elle n'était pas grecque ${ }^{54}$ :

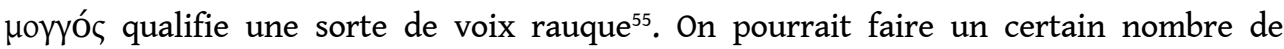
rapprochements pour Lillaia, mais ils relèveraient plutôt de la coïncidence, car ce serait

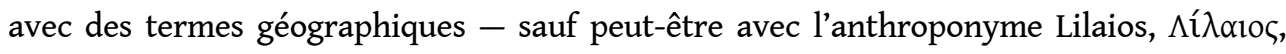
qui est porté par un noble Perse chez Eschyle ${ }^{56}$. Adara est le seul pour lequel j'avancerai une hypothèse. Il s'agit d'abord d'un mot magique, que relève Preisendanz; Étienne de

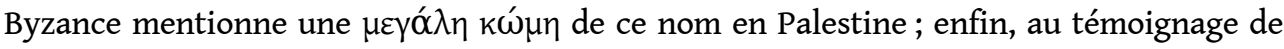
Flavius Josèphe, il existait dans l'empire perse et plus précisément chez les Juifs, un mois 'A $\delta \alpha \rho$, qui correspondait approximativement au macédonien Dystros ${ }^{57}$. Ce nom divin Adara peut donc être rapproché de ceux des deux fêtes des Nisanaia et des Aloulaia, dérivés eux aussi du vocabulaire calendaire. Nous sommes renvoyés une fois encore à l'Orient. Une telle origine est donc possible pour ces divinités.

\section{Le culte}

Au delà d'une liste des divinités honorées et de leur possible hiérarchie, l'inscription nous fournit toute une série d'indications sur le fonctionnement du sanctuaire, même si certaines d'entre elles, du fait de l'état de la pierre d'un côté, parce que nous avons affaire à un culte à mystères de l'autre, demeurent relativement obscures.

\section{Calendrier}

La face A contient un calendrier cultuel, qui énumère cérémonies et actes liturgiques à accomplir au cours d'un mois. Les noms de la quasi totalité des divinités figurent sur cette face, à l'exception d'Adara et Lilla, ces deux dernières étant peut-être mentionnées dans les parties perdues. En outre, la perte des vingt et une premières lignes interdit de savoir si le calendrier proprement dit était, comme c'est parfois le cas - mais cette disposition est loin d'être la plus fréquente -, précédé ou non d'une invocation aux dieux du type

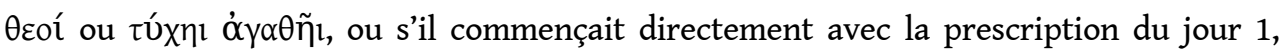
voire s'il était précédé de la mention de l'autorité responsable du règlement ${ }^{58}$. Quoi qu'il

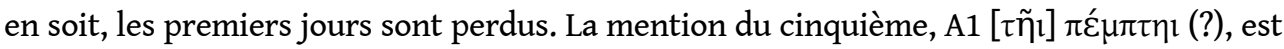
une possibilité, mais le mot est isolé, sur une ligne en très mauvais état. Le premier

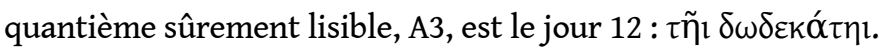

On lit ensuite sans difficulté, sur la partie bien lisible de la face, la séquence J12 à J19 : $\tau \tilde{\eta} 1$

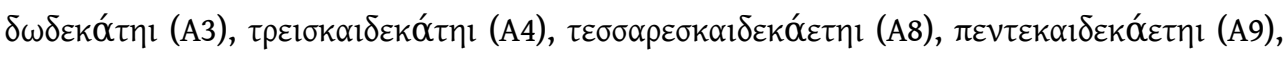

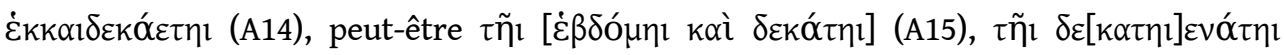

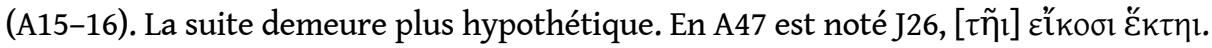

Était donc affiché un calendrier qui rappelait, sur un mois, les prescriptions rituelles régulières à observer. Ces dernières portent sur des questions de pureté, de modalités de sacrifice, et de processus d'initiation.

Sur la face B, mieux conservée, les indications calendaires se font rares. En B17 on

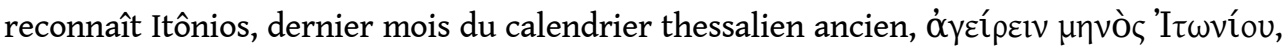

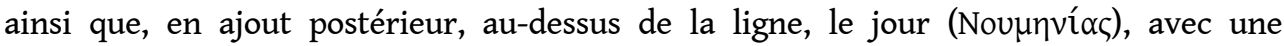

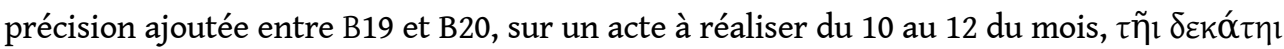

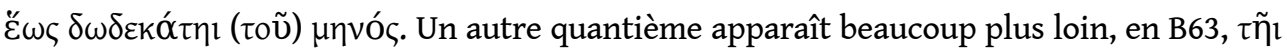

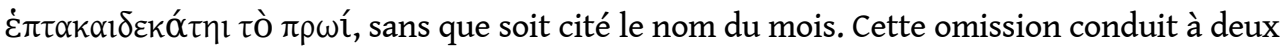


hypothèses. Soit il est fait allusion à un acte à réaliser le 17 de chaque mois, soit il s'agit d'un acte à accomplir le 17 Itônios, qui est la solution que je préfère, dans la mesure où ce mois est le seul cité sur la face. Dans ce cas, cette face $B$ lui est très largement consacrée. Les Aloulaia et les Nisanaia (B61) se seraient déroulées durant Itônios, soit en août / septembre, ainsi que, par hypothèse, les cérémonies d'initiation. Ces deux fêtes ont

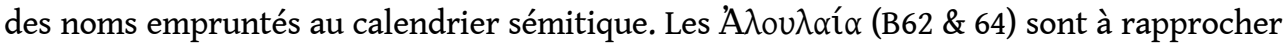
d'un anthroponyme proche-oriental connu sous deux graphies très voisines, $A \lambda \circ \lambda \alpha$ เo A $\lambda$ ou $\lambda \alpha{ }_{10} \varsigma^{59}$. M. Sartre rattache le premier au patronyme arabe al-' Ulayya. Pour le second, W.K. Prentice ${ }^{60}$ suggère qu'il s'agit d'un «birthday name ", formé à partir de ${ }^{\mathrm{C}}$ Aloul, nom de mois qui correspond à notre septembre. Le rapprochement avec le

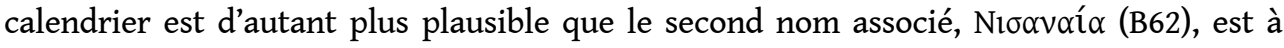

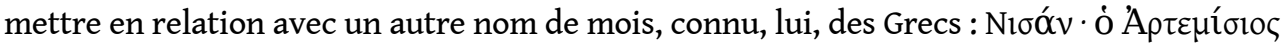
$\mu \eta ́ v$, Hésychius renvoyant ainsi au calendrier macédonien, adopté en Orient, et dans lequel Artémisios correspond à notre mois d'avril ${ }^{61}$. Ces deux fêtes sont donc tout à fait à leur place ici. Les Aloulaia parce qu'on constate une correspondance calendaire entre le mois grec Itônios et le sémitique 'Aloul. Les Nisanaia, puisqu'il s'agit, dans le calendrier grec, du mois d'Artémis, titulaire du sanctuaire de Marmarini.

\section{Personnel attaché au culte}

Le personnel attaché au culte compte d'abord une prêtresse chargée, avec le néocore, de

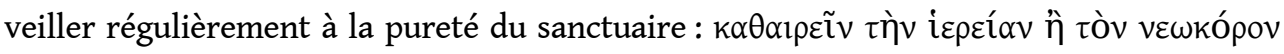
(B4). Cette prêtresse, qui intervient à propos de l'autel de Moire, est celle qu'on retrouve

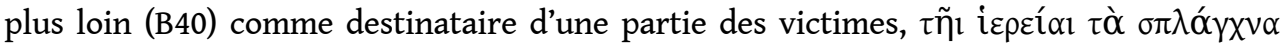

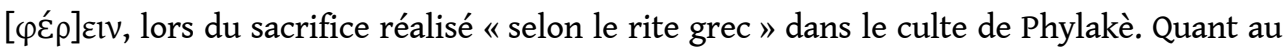
néocore, qui apparaît à plusieurs reprises, il est, sans surprise, chargé des tâches de

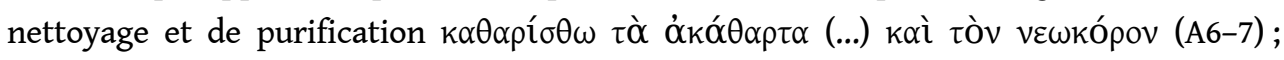

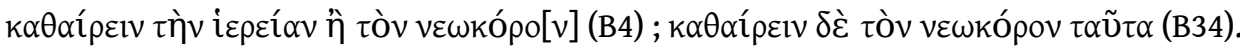

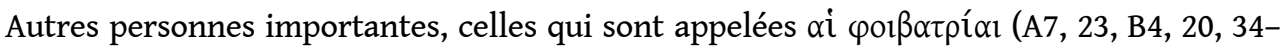

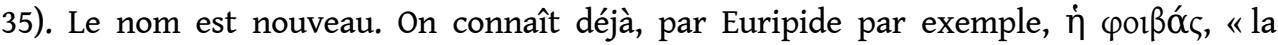

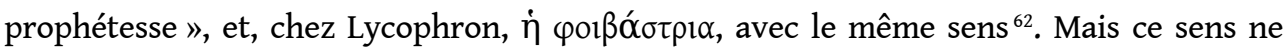

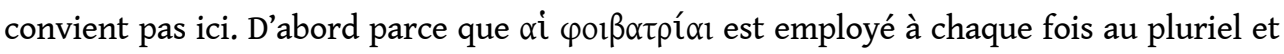
qu'il serait étonnant qu'il y eût plusieurs prophétesses en même temps, d'autant que leur nombre n'est pas précisé. Ensuite et surtout parce que leur rôle semble se limiter, comme le néocore auquel elles sont régulièrement associées, à la purification du sanctuaire :

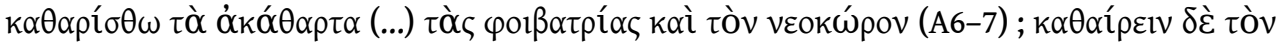

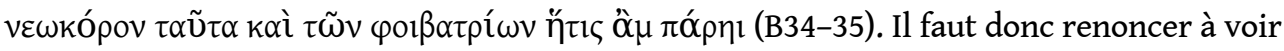

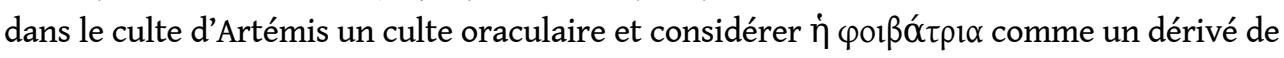
poıßó $\omega$ au sens de "nettoyer, purifier», verbe connu surtout dans le vocabulaire

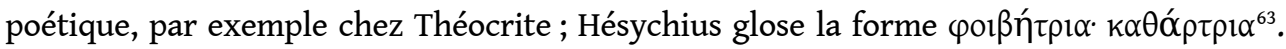

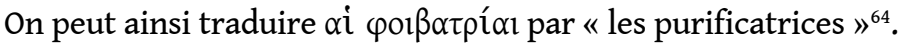

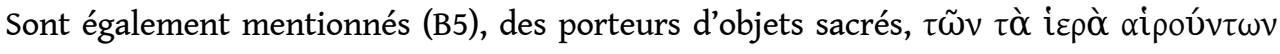

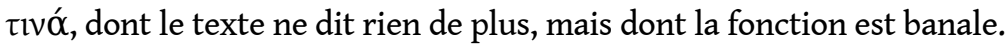




\section{Interdictions et pureté rituelles}

Le règlement édicte une série d'interdictions et donne des indications sur la manière de réparer leur viol éventuel. Dans l'ensemble, elles sont classiques et peuvent se répartir en plusieurs catégories.

D'abord une double interdiction générale, qui touche toutes les impuretés ${ }^{65}$, sans précision sur leur nature exacte, y compris celles qui concernent plus spécifiquement les

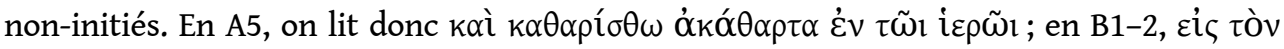

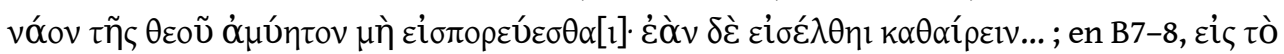

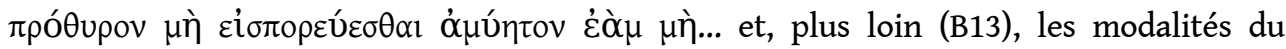
sacrifice de purification ${ }^{66}$. Une double interdiction spécifique, en outre, porte sur le grand

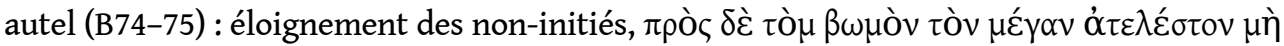

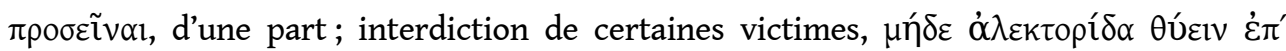

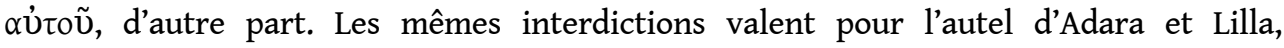

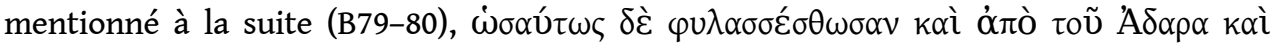
$\Lambda \imath \lambda \lambda \alpha \beta \omega \mu$ vo.

On repère ensuite une série d'interdictions traditionnelles touchant les femmes: la

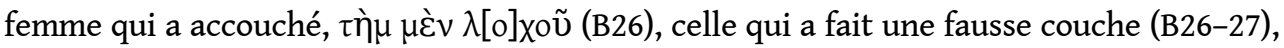

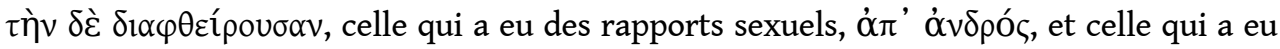

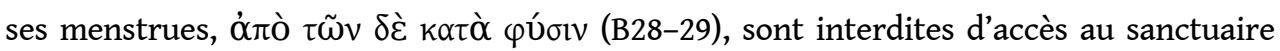
pour des durées variables, d'une semaine, pour ces deux derniers groupes, à quarante jours pour la fausse-couche ${ }^{67}$. Même si le culte principal du sanctuaire est celui d'Artémis et si une bonne partie du personnel (la prêtresse, les purificatrices) est féminin, nous ne nous trouvons pas en présence d'un culte réservé aux femmes. D'abord parce qu'il est

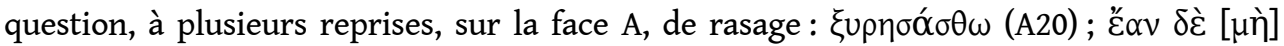

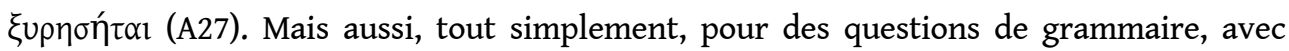

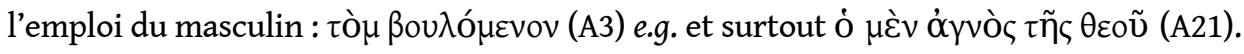

39 À la fin et comme si elles avaient été ajoutées au dernier moment, sont mentionnées trois sources habituelles de pollution : on ne doit ni uriner ni saigner dans le sanctuaire, દ̇ò $v$

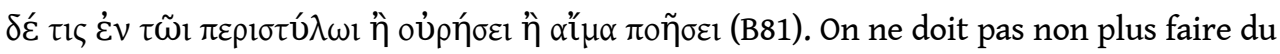

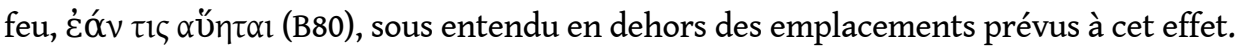

'eau jouait un rôle important ${ }^{68}$. D'abord, cela n'a rien d'étonnant dans des rites de purification, lorsqu'il fallait emplir la jarre d'eau à la source du sanctuaire, puis l'ouvrir,

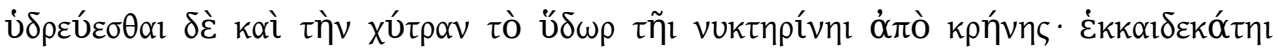

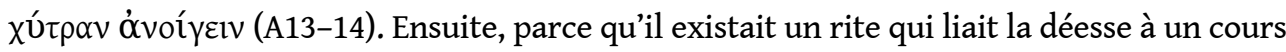

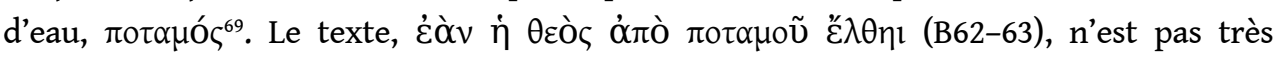
explicite. Plutôt qu'à un bain rituel de la statue, possible cependant, il pourrait être fait référence à l'arrivée de la déesse depuis le fleuve ou la rivière, arrivée qui n'était pas, au moins dans le mythe, totalement assurée si l'on prend ćóv au pied de la lettre. Ce pourrait donc être une allusion à un mythe de fondation du sanctuaire, même si je resterai très prudent sur ce point en raison du caractère allusif du passage ${ }^{70}$. On sait que le culte d'Artémis a des liens avec les eaux douces, stagnantes ou courantes : la déesse se nomme ailleurs, selon Pausanias ou Strabon, entre autres, $\Lambda \iota \nu v \tilde{\alpha} \tau \iota \varsigma, ~ \Lambda \iota \mu v \alpha i ́ \alpha, \Sigma \tau v \mu \varphi \eta \lambda i ́ \alpha$, À $\lambda \varphi \varepsilon i \alpha i ́ \alpha$, 'A $\lambda \varphi \varepsilon i \omega v i \alpha^{71}$. Reste que le cours d'eau de la lex sacra n'est pas nommé et que

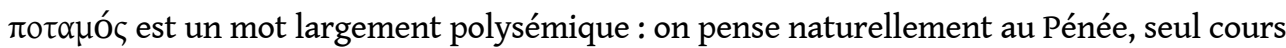


d'eau de quelque importance dans le secteur, qui ne coule pas très loin de Marmarini et qui pourrait parfaitement être lié au récit de l'arrivée de la déesse depuis la mer où il se jette. J'ajoute que, sur la feuille Platykambos de la carte topographique du Service géographique des armées, figure un marécage ou plutôt une zone humide, nommé $\Lambda$ í $\beta \delta \delta$,

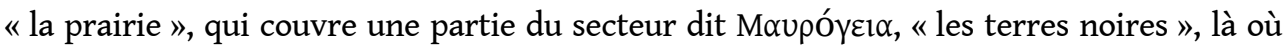
l'on a trouvé la pierre, deux termes signalant des lieux humides. C'est l'une des raisons qui m'avaient conduit à supposer que le sanctuaire d'Artémis se trouvait à faible distance du lieu de dépôt de la stèle. Mais en réalité la pierre a pu être apportée d'assez loin.

Quoi qu'il en soit, le sanctuaire décrit dans le règlement est clairement un sanctuaire hors les murs, un sanctuaire "de campagne », comme l'indiquent les mentions d'une source et surtout d'une vigne ${ }^{72}$. On peut alors revenir sur la question éludée au début, celle de sa localisation, sinon toute proche, du moins à faible distance de son lieu de découverte moderne (Fig.4). Marmarini n'est tout d'abord guère éloigné de l'emplacement de

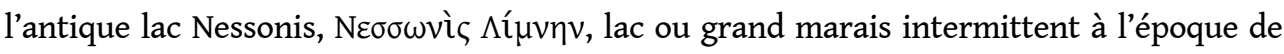
Strabon $^{73}$, aujourd'hui drainé. Le village se trouve surtout à une courte distance d'un petit

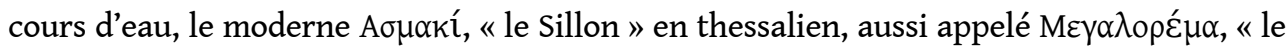
Grand torrent ». B. Helly, avec de bons arguments, a proposé de l'identifier à l'antique 'Auvpos, connu par une mention d'Apollonios de Rhodes, et qui porta sans doute aussi le nom de Pénée ${ }^{74}$. Ce cours d'eau rejoint le Pinios moderne juste au nord d'Omorphochôri

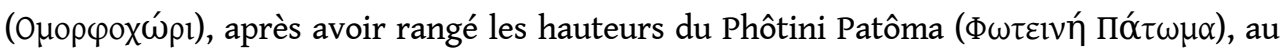
pied duquel sortent plusieurs grosses sources. Ainsi peut-on proposer, au moins par hypothèse, que le sanctuaire d'Artémis Phylakè se trouvait quelque part au sud-ouest du village moderne de Marmarini, à proximité du Pénée et du lac Nessonis, dans la direction de Larissa, à une quinzaine de kilomètres de là, sur le territoire de la cité thessalienne ${ }^{75}$.

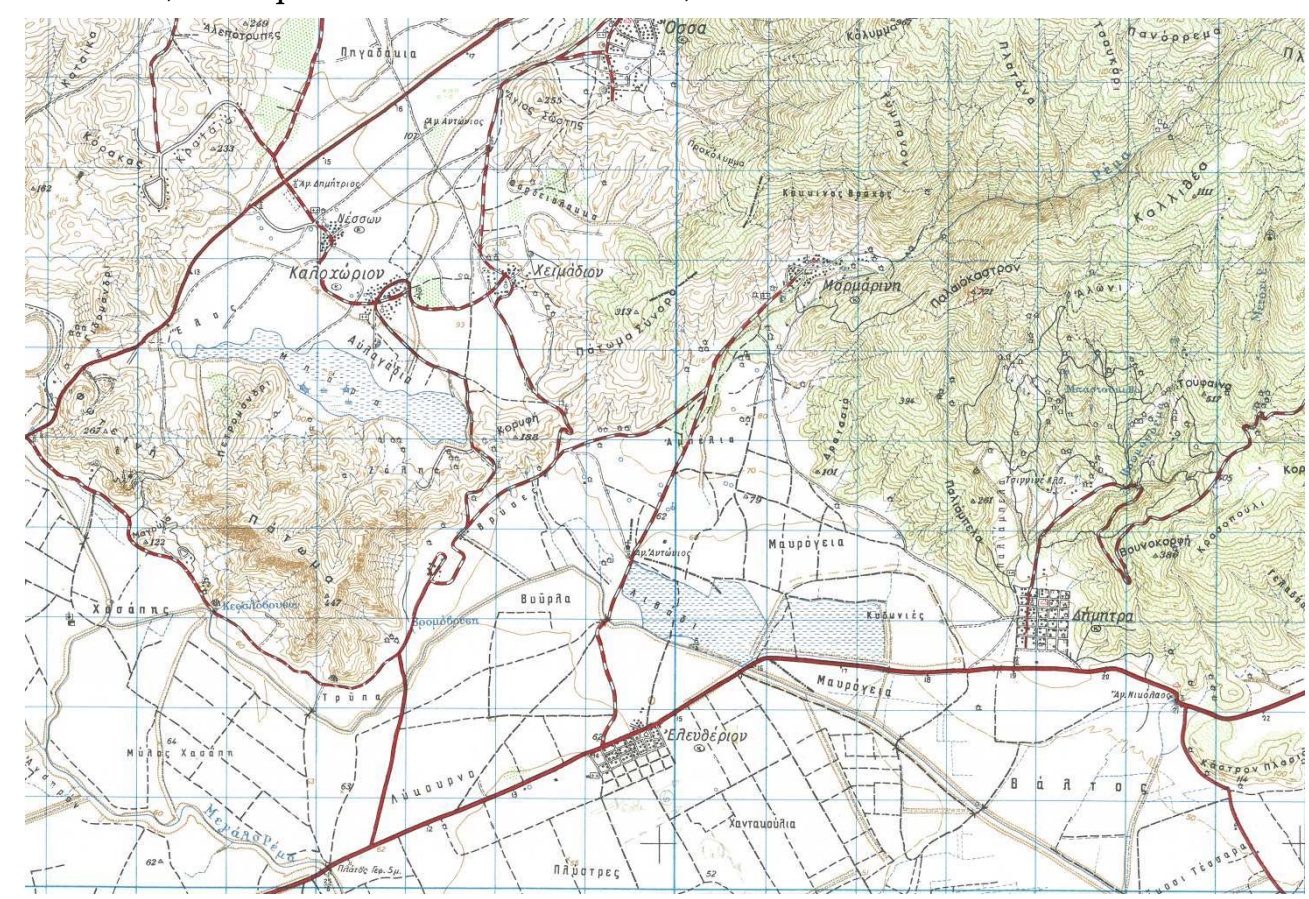

Fig. 4. Marmarini et ses environs

Service géographique des armées, Grèce. 


\section{Offrandes et animaux sacrificiels}

42 Avant de regarder ce qui concerne les animaux offerts, on ouvrira une rapide parenthèse sur le vocabulaire du geste sacrificiel que propose ce texte. Celui-ci, en effet, utilise une palette verbale particulièrement riche. Même si elle ne fait pas appel à l'ensemble des composés étudiés naguère par Casabona ${ }^{76}$, il est rare que, dans un seul texte, le choix soit

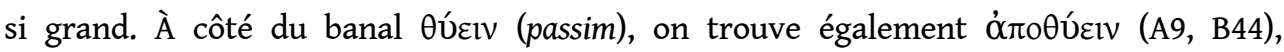

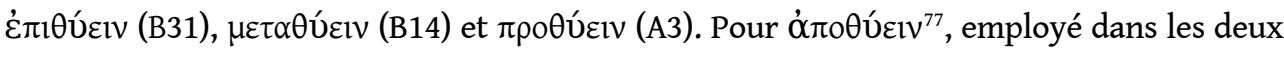
cas absolument, les parallèles, littéraires ou épigraphiques, ne permettent pas de

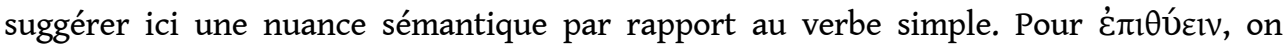
pourrait admettre une nuance temporelle, ce sacrifice prenant place soit après un autre, soit en plus d'un autre et donc aussi après un premier : les emplois épigraphiques attestés vont, pour certains, dans ce sens, mais d'autres ne lui donnent qu'un sens finalement très neutre ${ }^{78}$. Quant à $\pi \rho \circ \theta \tilde{v}^{2} v^{79}$, sans qu'on puisse en être sûr, puisque le verbe se trouve au début du texte conservé, la valeur d'antériorité est sans doute aussi ici la bonne, "sacrifier d'abord, faire un sacrifice préliminaire", même si d'autres sens comme

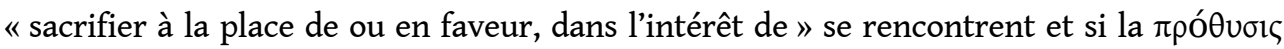
est une pratique connue ${ }^{80}:$ le $12 \mathrm{du}$ mois a lieu un sacrifice préliminaire, avant une série

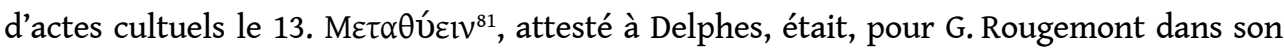
étude sur le cippe des Labyades, un hapax, " embarrassant », pour Casabona ${ }^{82}$ : il s'agit d'offrir un sacrifice expiatoire, pour apaiser le dieu, après une action contraire au rite. Dans notre texte, le verbe parait avoir un sens différent, plus banalement temporel, puisque la purification rituelle est assurée par le verbe qui précède directement sur la

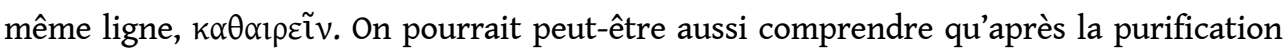
on procède à un nouveau sacrifice, avec une autre victime, le premier étant considéré comme nul et non avenu ${ }^{83}$.

Si l'on examine les offrandes qu'il est ordonné de faire lors des différentes purifications ou sacrifices, on peut faire plusieurs remarques.

À trois reprises au moins, selon un usage fréquent, le choix est laissé au dédicant et ce

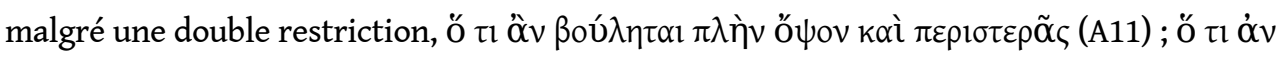

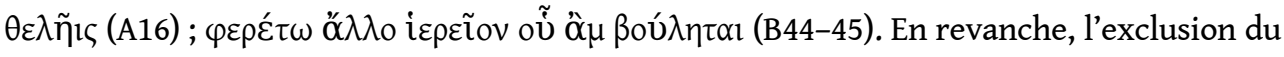
porc est répétée trois fois au moins, on l'a vu.

Les sacrifices sanglants consistent essentiellement en volailles et en petit bétail. Il y a dans cette liste une gradation de l'offrande la moins à la plus importante et si les oiseaux réapparaissent à la fin, c'est que ce sont les seuls, avec les caprins, à faire l'objet d'un

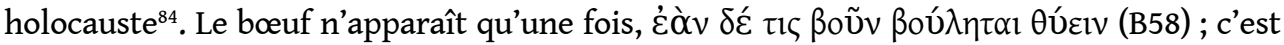
la dernière victime et la moins citée, la plus rare, la plus coûteuse aussi. Les caprins ne

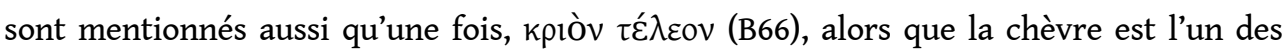
animaux favorits pour Artémis ; ils le sont pour un holocauste ${ }^{85}$. Les ovins sont beaucoup

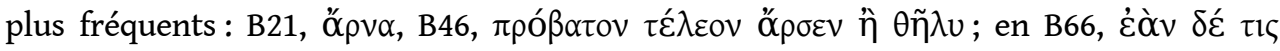
ò sont choisis, par défaut, à la place du bouc; en B25-26, il est question aussi d'agneaux et d'agnelles, $\alpha_{\rho} v i ́ \alpha$, diminutif qui est un mot rare. L'essentiel est constitué d'oiseaux domestiques, ǒpvic (A25, B 31, 54), le terme désignant généralement des volailles. Le

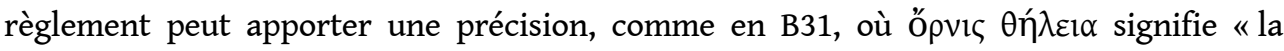

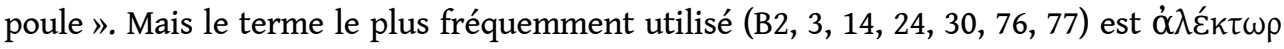


qui est un mot relativement rare et d'emploi plutôt poétique, pour $\dot{\alpha} \lambda \varepsilon \kappa \tau \rho v \omega ́ v$, et qui désigne généralement le coq. Dans notre inscription, cependant, le mot apparaît plutôt comme un simple synonyme de ópvic, puisqu'on distingue à deux reprises (á $\lambda \varepsilon \kappa \tau o ́ p l$

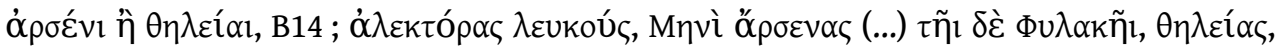
B24), la volaille mâle de la femelle, le coq de la poule; de la même manière, une

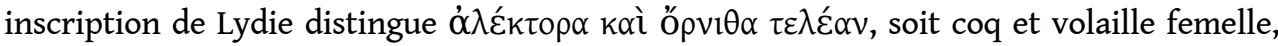

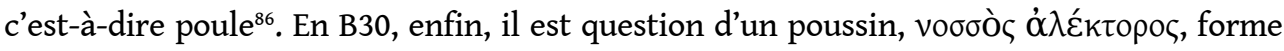

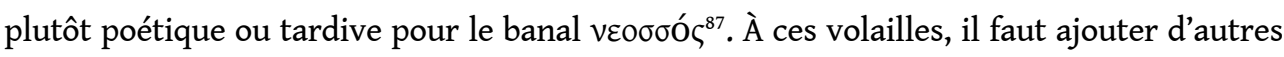
oiseaux domestiques : la colombe, $\pi \varepsilon p 1 \sigma \tau \varepsilon \rho \tilde{\alpha}$ (A11), qui est exclue du sacrifice ; l'oie, $\chi \eta ் v$ $(B 55,70)$, qui peut être offerte en holocauste ${ }^{88}$, tout comme la caille, ö (B73) est cité un animal associé à la caille et qui est donc vraisemblablement un volatile de petite taille, la $\tau p u ́ \beta \beta \alpha$. Le mot est nouveau, mais on peut peut-être le rapprocher de $\tau \rho u \gamma \omega ́ v$, la tourterelle. Cependant la mention de la colombe et de son exclusion du sacrifice rendent ce rapprochement douteux. On peut le rapprocher aussi de celui du $\tau \rho u ́ \gamma \gamma \propto \varsigma^{89}$. Les différentes identifications proposées pour ce dernier oiseau (bécasseau, bergeronnette, hochequeue, plongeur) ont été mises en doute par D'Arcy Thompson et elles ne conviennent pas non plus ici, car il s'agit toujours d'espèces sauvages. Pour la

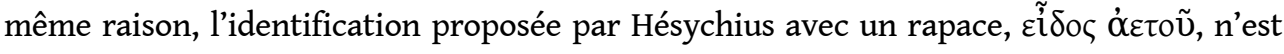
pas acceptable : on ne sait donc pas ce qu'est la tpú $\beta \beta \alpha$. Enfin le poisson apparaît à deux

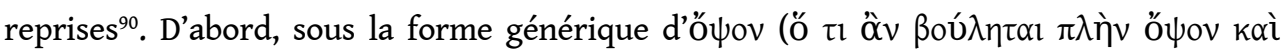
$\pi \varepsilon \rho i ́ \sigma \tau \varepsilon \rho \alpha \varsigma$, A11), qui ne dit rien de l'espèce dont il s'agit, il est interdit dans le culte de Pan. Ensuite, sous le nom d'ónorupíc, qui dit plus sur la manière de le cuire, en fait de le

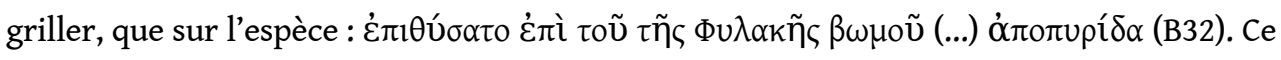
nom nous a été transmis par Athénée. Chez Hégésandros de Delphes, c'est un poisson d'eau douce du lac Bolbè, en Macédoine ${ }^{91}$; on pourrait ainsi penser à de petits poissons venant du lac Nessonis ou du Pénée. Mais certaines sources en font un poisson de mer. D'après Cléarque, le flûtiste Technôn en aurait fait griller en offrande sur la tombe de son ami Charmos, selon un usage funéraire que l'on retrouve sur une dédicace de $\operatorname{Cos}^{92}$.

Du partage des victimes et de ce qui revient à la prêtresse, il est peu question dans

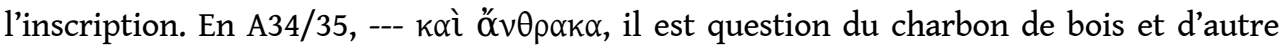
chose - mais le texte est en mauvais état. En B40-43, le texte est plus précis et énumère

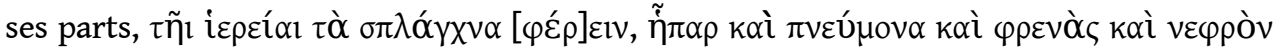

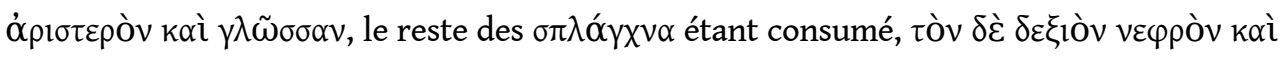

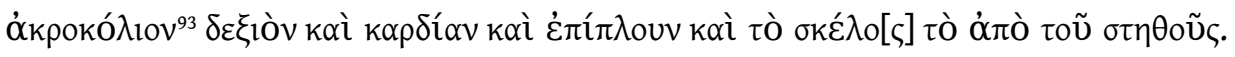

Les fournitures qui sont réclamées pour les différents rites de purification ou les sacrifices ne présentent guère d'originalité. Le fidèle doit apporter de l'huile pour les

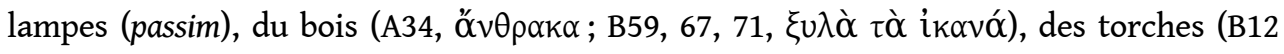

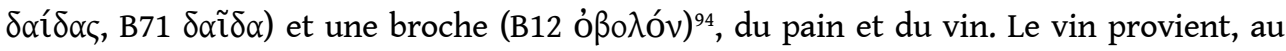

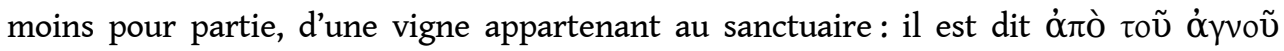

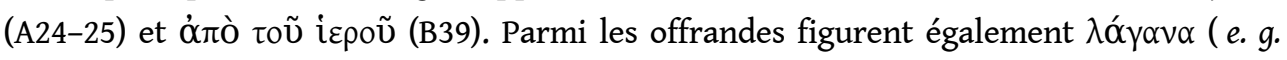
A24, 32, B15, 37, 68) et óuópa (B38, 47, 59, 69). Les premiers sont connus par Athénée, Galien et Hésychius ${ }^{95}:$ il s'agit d'une sorte de gâteau sec, de qualité inférieure, si l'on en croit Galien : Kearns, dans son relevé des gâteaux offerts lors des sacrifices, l'ignore ${ }^{96}$. On ne connaît du reste qu'un exemple épigraphique du terme, un graffite d'Antioche ${ }^{97}$. La

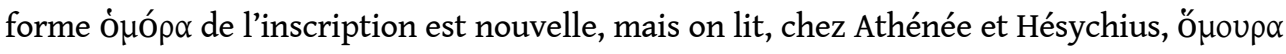
et $\dot{\alpha} \mu o ́ \rho \alpha^{98}$ : il s'agit d'une bouillie de fleur de froment, donc de qualité supérieure, à la 
différence des lagana, aromatisée au miel et au sésame. Sont mentionnés enfin quelques

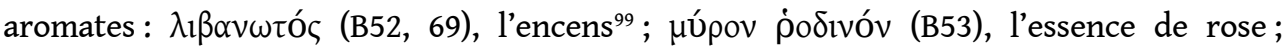

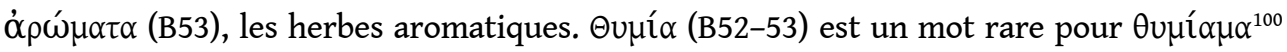
et est traduit par encens, mais le sens ne convient pas ici, puisque cela ferait doublon avec $\lambda_{1} \beta \alpha v \omega \tau$ tó , sauf à y reconnaître une catégorie spéciale d'encens. Z $\mu$ ó $\rho v \alpha$ ou $\sigma \mu u ́ \rho v \alpha$ (B53, 69) est la myrrhe, qui, outre son usage funéraire, est utilisée pour des fumigations. La

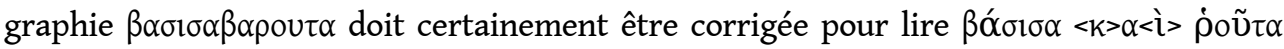
(B69, B72), deux mots à rapprocher d'une description de Dioscoride, De materia medica 3 , $45-46^{101}$, et qui correspondent à une seule plante, la rue, Ruta L., en grec $\pi \eta ́ \gamma \alpha v o v$, dont il

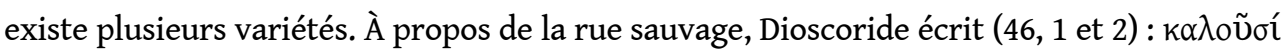

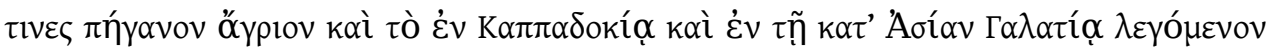

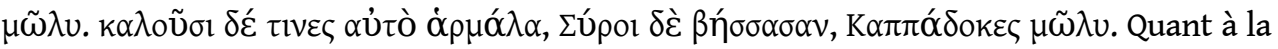

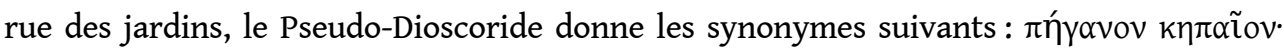

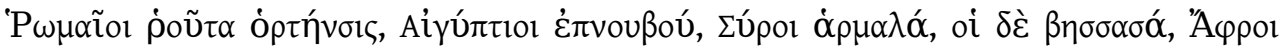
xoupuá. La rue est donc citée deux fois, ou deux variétés de la même plante, l'une sous la

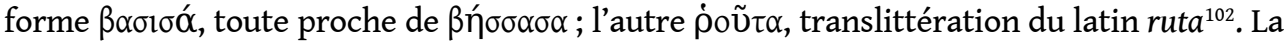
syllabe parasite $-\beta \alpha$ - s'expliquerait par une mélecture de $\kappa \alpha(i)$ ), avec chute du iota final. Cette plante vivace, qu'on trouve en abondance dans les régions méditerranéennes et en Asie du Sud-Ouest a un usage médicinal (c'est un abortif) et culinaire (du moins à Rome) ; certaines variétés sont utilisées en fumigations et leurs effets psychotropes sont connus encore de nos jours en Turquie ou Asie centrale. Si l'harmale est fréquente dans les plaines thessaliennes ${ }^{103}$, le terme $\beta \alpha \sigma \tau \sigma \alpha ́$ nous renvoie, une fois encore, en Orient.

Plusieurs précisions relatives à des célébrations qui sortent de la routine, qui apparaissent sur la face $B$, méritent d'être relevées.

Je n'insisterai pas sur la mention de plusieurs holocaustes, à trois reprises $(\mathrm{B} 66,70,73)$,

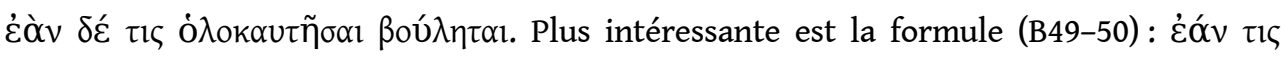

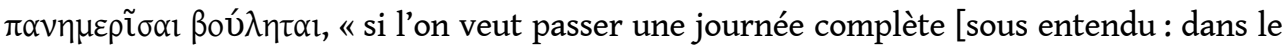

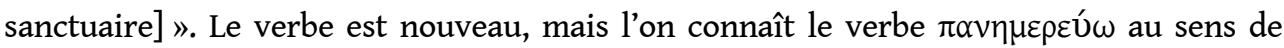
" consacrer une journée à une activité », en particulier de nature religieuse ou festive, par une unique mention dans le Rhésos d'Euripide, à propos d'un thiase ${ }^{104}$.

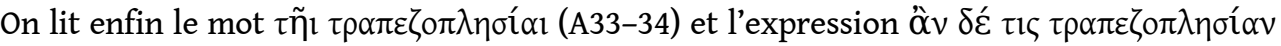

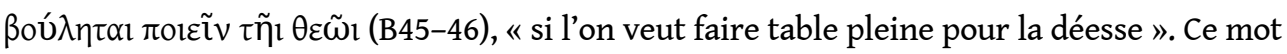
est aussi un hapax, que l'on peut rapprocher du verbe $\tau \rho \alpha \pi \varepsilon \zeta о \pi о 1 \varepsilon ́ \omega$, qui signifie « garnir

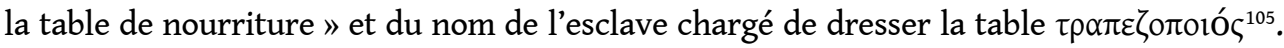
À Marmarini, la table sacrificielle doit être entièrement couverte de nourriture et l'énumération qui suit : viande de mouton, bouillie, gâteaux, vin, va bien en ce sens.

51 Enfin le rituel comportait plusieurs processions. Une lors des Nisanaia, ع́ $\sigma \tau \omega \delta \varepsilon \dot{~} \dot{\eta} \pi 0 \mu \pi \grave{\eta}$

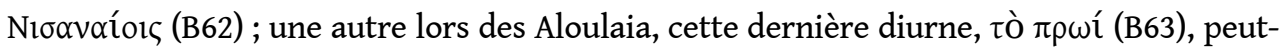
être au lever du jour ; une troisième, nocturne, se déroulait aux flambeaux, apparemment

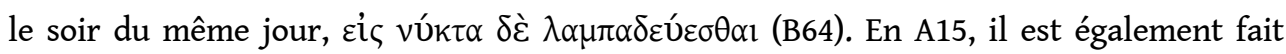

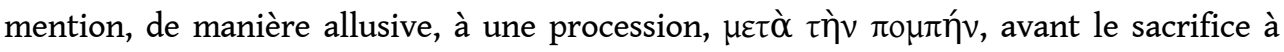
Alaia, mais il n'est pas possible de dire s'il s'agit d'une des trois dont nous venons de parler ou d'une procession supplémentaire ${ }^{106}$. 


\section{Un culte à mystères}

52 Je serai extrêmement prudent en présentant cet aspect, pourtant fondamental, de l'inscription, en particulier parce que la majorité des indications sur ce point se trouvent sur la face A, la plus abîmée.

Une première chose est sûre. Le texte permet de distinguer deux catégories de personnes, les initiés et les autres ${ }^{107}$. De ces derniers, il est surtout question, du moins dans l'état de notre déchiffrement, sur la face $B$, parce que c'est sur celle-ci que figurent les

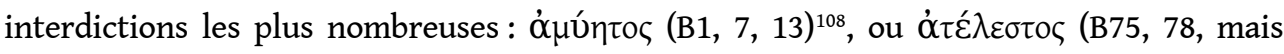

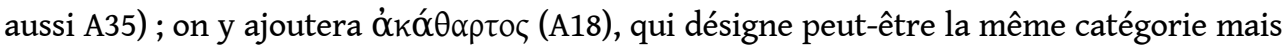
aussi, comme en A23, un initié souillé par une impureté quelconque. C'est l'une des raisons pour lesquelles je me suis demandé si le texte ne débutait pas par ce que nous appelons la face B : on commence par exclure avant de donner des indications positives, j'y reviens plus loin. Sur la face A, en revanche, ce sont les mystes qui sont mentionnés et

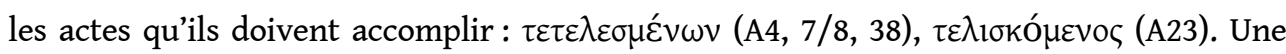
particularité mérite d'être signalée à propos de ces mystes, même s'il s'agit d'un passage (A25-26) particulièrement difficile à déchiffrer et à comprendre : ces derniers paraissent

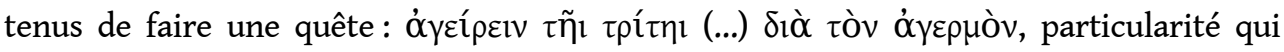
accentue le caractère " orientalisant » du rituel. Les modalités n'en sont pas précisées, mais il est clair que la cité n'est en rien concernée.

Une autre indication du texte va tout à fait dans le même sens. Une partie des cérémonies

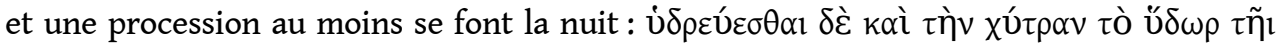

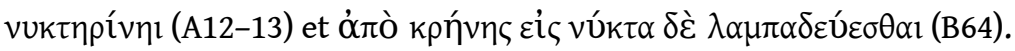

L'association d'Artémis à des cultes à mystères, affirme M. Jost dans la liste, non exhaustive, qu'elle en a donnée, n'est pas très fréquente, alors que F. Graf va plutôt à l'encontre de cette opinion ${ }^{109}$. Si effectivement, en Arcadie du moins, de tels cultes sont moins fréquents que ceux de Déméter et n'apparaissent que sur le Mont Knakalos, près de Kaphyai, et à Lykosoura, où Artémis est associée à Despoina, il existe cependant des témoignages assez nombreux, à travers le monde grec, de ceux que Graf nomme les Lesser mysteries, les mystères secondaires, à Thasos, Mytilène, Cyrène, Didyme et, bien entendu, Éphèse. À Athènes même, si l'on se fie à une scholie à Théocrite ${ }^{110}$, le culte d'Artémis comportait aussi des mystères. Les plus célèbres sont certainement ceux du sanctuaire

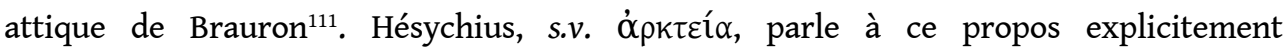
d'initiation, $\tau \varepsilon \lambda \varepsilon \tau \eta ́$, et le scholiaste à Aristophane, Lysistrata 645a, de mystère, ö $\rho \kappa \tau o v$

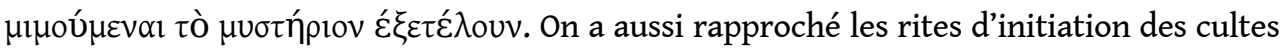
d'Artémis et de Déméter comme étant la double face d'un même phénomène, le passage à l'âge adulte, celui d'Artémis en marquant le point de départ, celui de Déméter le point d'arrivée. Que ces deux déesses aient, en Thessalie, la même épiclèse de Phylakè pourrait aller dans le même sens.

Reste à savoir si notre texte fournit des indices sur le rituel. J'en ai déjà évoqué quelques uns. Il me semble en effet que, peut-être, la table pleine et la journée complète consacrée

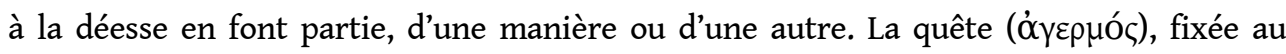
premier du mois Itônios et qui ne doit pas durer plus de trois jours (B17-18), avec déplacement des objets sacrés, aussi, en préliminaire sans doute. C'est cependant la face A qui devait fournir le plus de détails, mais, pour nous de manière frustrante. Je relèverai 
une double obligation pour celui qui souhaite subir l'initiation (A19-21) : l'obligation de se

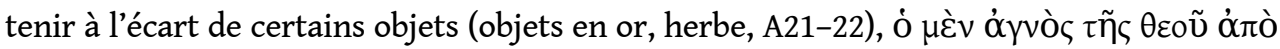

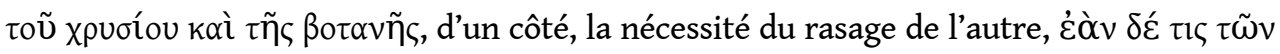

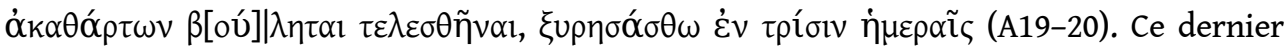
point parait important. L'offrande, partielle ou totale, de la chevelure ou de la première barbe est connue en Grèce. Mais il s'agit à Marmarini de tout autre chose : un rasage (de la tête seule ou de tout le corps, on ne sait) comme expression de la pureté rituelle, manifestant l'entrée dans la sphère du sacré et que l'on retrouve en Égypte, mais aussi au Proche-Orient ${ }^{112}$ : à Palmyre, les prêtres ont la tête et la barbe rasées, comme les notables d'Héliopolis-Baalbek, et Lucien signale qu'il s'agit d'une obligation rituelle pour le pèlerin ${ }^{113}$ dans son traité sur la Déesse syrienne. Une fois encore les rituels décrits dans l'inscription nous rattachent à l'Orient ${ }^{114}$. On pourrait y ajouter un autre indice qui va dans le même sens : il est demandé à l'initié de faire la quête, malheureusement dans un

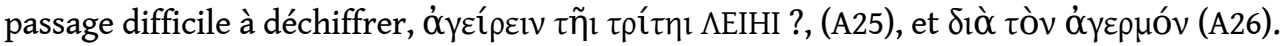
J'ajoute, pour conclure sur ce point, qu'il est aussi question, à plusieurs reprises (A26, 28) d'une corbeille oxoívov $(\mathrm{A} 30,36)$ d'un bassin ( $\sigma \kappa \alpha ́ \varphi \eta)$, qui pourraient participer du rituel sans qu'on puisse aller plus loin.

\section{Le responsable de l'inscription}

Reste une dernière question, celle de l'autorité qui a fait graver ce texte. Je ne peux avancer que des hypothèses dans la mesure où, précisément, aucune autorité n'est explicitement citée : il n'y a pas la place sur la face B et le début de la face A, si cette dernière est bien le recto de l'inscription, est totalement illisible. Nous ne lisons donc pas d'intitulé. On pourrait faire l'hypothèse qu'il existait une autre stèle, où apparaissaient l'autorité responsable de la gravure et éventuellement d'autres prescriptions rituelles, peut-être même des précisions sur le culte «non grec $»^{115}$. Nous n'avons aucun argument en faveur de l'existence d'une telle stèle et l'admettre ne ferait que déplacer voire compliquer inutilement le problème.

Un fait au moins est assuré. Le rédacteur du texte est certainement un Grec, du fait qu'il maitrise fort bien la langue, comme le prouve, entre autres arguments, son usage de $\theta u ́ \omega$ et de ses différents composés, voire celui de mots rares. Trois possibilités s'offrent à nous, dont on peut trouver des parallèles ailleurs. Soit le règlement se présente, si l'on peut dire, à l'état brut, sans intitulé, avec simplement, par exemple, une invocation du type

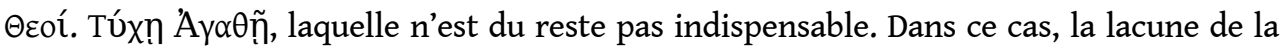
face A (21 lignes) ne comporterait que les consignes pour les quatre premiers jours, ce qui paraît possible, mais gênant, car un peu long. Soit le règlement est issu de la cité, en l'occurrence Larissa, et l'intitulé est celui d'un décret, qui occupe une certaine place dans la lacune, suivi des premières prescriptions. Dans ce cas, le culte de Phylakè et des autres divinités serait pour ainsi dire intégré à la vie de la cité. On pourrait trouver un parallèle dans la place faite à Athènes, à partir de 429 , au culte de la déesse thrace Bendis, souvent assimilée elle aussi à Artémis, culte qui, à la suite d'un oracle de Dodone, figure au nombre des cultes de la cité ${ }^{116}$. Soit enfin, comme pour l'inscription installant le culte de Mên en Attique ${ }^{117}$, nous sommes en présence d'une inscription de fondation, qui mentionne le nom du fondateur ou, peut-être mieux dit, de l'introducteur du culte dans la région, ou encore de l'association « propriétaire ou gestionnaire » du sanctuaire. En A3/4,

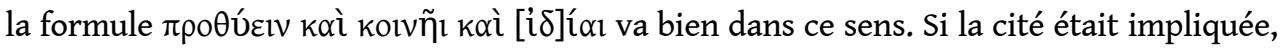




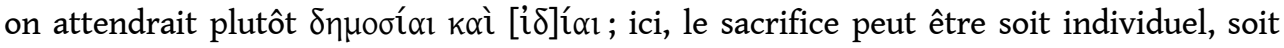
collectif, mais non pas civique ${ }^{118}$. Dans ce cas-là, l'insistance mise sur l'existence de deux rites, un grec et un qui ne l'est pas, pose la question, très vaste, des processus d'intégration des cultes étrangers en Grèce, question qui dépasse évidemment le cadre du présent travail. Il est clair, en tous cas, que le rédacteur met nettement l'accent sur deux modalités différentes d'un même culte avec des divinités grecques (ou faut-il dire « hellénisées »?) et d'autres qui sont à l'évidence étrangères, venues d'Anatolie orientale ou bien plutôt de Syrie. On pourrait alors parler d'une acculturation incomplète, même si le terme peut paraître anachronique. Je ne trancherai pas définitivement, mais il me semble malgré tout que cette dernière solution est préférable, précisément dans la mesure où, d'une part, le texte établit clairement une distinction entre deux rites et que d'autre part plusieurs divinités ne font pas l'objet d'une interpretatio graeca, l'assimilation de Phylakè à Artémis étant en outre limitée, comme on l'a vu supra.

\section{Conclusion}

L'inscription de Marmarini nous apporte donc toute une série de nouveautés. D'abord sur les cultes en Thessalie, avec en particulier l'existence d'un culte à mystères, consacré à Artémis Phylakè, dans un sanctuaire où, à côté de divinités bien connues, étaient également honorées des divinités féminines jusqu'alors inconnues et d'origine certainement orientale. Les détails donnés sur l'un des deux rites pratiqués - le rite grec, l'autre n'étant pas décrit sur la pierre - nous fournissent en outre bon nombre de mots nouveaux, même si les indications sur l'initiation demeurent pour nous limitées. Nul doute que cette inscription, dont il est difficile de savoir qui en était à l'initiative, donnera, dans les années à venir, matière à discussion.

\section{BIBLIOGRAPHIE}

S. AMIGUES, « Des plantes nommées moly », JS (1995), p. 3-29.

A.S. ARVANITOPOUlos, «Inscriptions inédites de Thessalie », RPh 35 (1911), p. 123-139.

C. AUFFARTH, s.v. « Bendis », Brill's NP II (2003), col. 593-594.

J.-F. BOMMELAER, Guide de Delphes. Le site, Paris, 1991.

L. BODSON, IEPA ZSIA. Contribution à la place de l'animal dans la religion grecque ancienne, Bruxelles, 1978.

L. BODSON, « L'initiation artémisiaque », in L. RIES, H. LIMET (éd.), Actes du colloque de Louvain la Neuve sur les rites d'initiation 1984, Louvain, 1986, p. 299-315.

R. BOUCHON, B. HELLY, «Construire et reconstruire l'État fédéral thessalien (époques classique, hellénistique et romaine). Cultes et sanctuaires thessaliens ", in P. FUNKE, M. HAAKE (éd.), Greek Federal States and their Sanctuaries. Identity and Integration, Stuttgart, 2013, p. 205-226. 
R. BOUCHON, A. TZIAFALIAS, «Les cités thessaliennes et Néron : à propos d'une inscription inédite de Larissa », Neronia electronica 3 (2014), p. 3-11.

M. BOYCE, F. GRENET, A history of Zoroastrianism III, Leyde, 1991.

L. BRUIT ZAIDMAN, « Le parfum et l'encens dans les offrandes et les sacrifices », in E. VERBANCKPIÉRARD, N. MASSAR, D. FRÈRE (éd.), La rose et l'encens en Méditerranée. Catalogue de l'exposition du musée royal de Mariemont, Bruxelles, 2008.

J.-M. CARBON, « Monographing Sacred Laws », Kernos 25 (2012), p. 318-327.

J.-M. CARBon, V. PIRENNE-DELFORGE, « Beyond Greek Sacred Laws », Kernos 25 (2012), p. 163-182.

J. CASABONA, Recherches sur le vocabulaire des sacrifices en grec, des origines à la fin de l'époque classique, Aix-en-Provence, 1966.

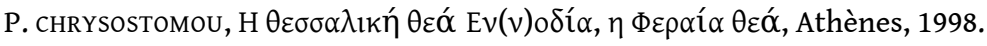

K. CLINTON, «Pigs in Greek Rituals », in R. HÄGG, B. ALROTH (éd.), Greek Sacrificial Rituals, Olympian and Chthonian, Stockholm, 2005, p. 165-179.

M.B. cosmopoulos (éd.), Greek Mysteries: the Archaeology and Ritual of Ancient Greek Secret Cults, Londres / New York, 2003.

T. CORSTEN, « Herodot I-131 und die Einführung des Anahita Kultes in Lydien », IA 26 (1991),

p. $163-180$.

W. D'ARCY THOMPSON, Glossary of Greek Fishes, Londres, 1947.

W. D'ARCY THOMPSON, Glossary of Greek Birds, Londres / Hildesheim, 1936 [1966].

S. DE ANGELI, s.v. « Moirai », LIMC VI (1992), p. 636-648.

J.-C. DECOURT, « Cultes et divinités isiaques en Thessalie », in L. BRICAULt, M.J. VERSLUYS, P.G.P. мЕувоом (éd.), Nile into Tiber. Egypt in the Roman World 200 BC - AD 400. Proceedings of the III ${ }^{\text {rd }}$ International Conference of Isis Studies, Leiden, May 11-14 2005, Leyde / Boston, 2007, p. 329-363.

J.-C. DECOURT, « Les cultes thessaliens dans l'Alexandra de Lycophron », in C. CUSSET, É. PRIOUX (éd.), Lycophron : éclats d'obscurité. Actes du colloque international de Lyon et Saint-Étienne 18-20 janvier 2007, Saint Étienne, 2009, p. 377-391.

J.-C. DECOURT, « Cultes et sanctuaires à Crannon (Thessalie) », in M. STAMATOPOUlou (éd.), Cults and Sanctuaries in Ancient Thessaly. Proceedings of the International Colloquium Held at the British School at Athens, 11/30 - 12/1 2012, Athènes, sous presse.

J.-C. DECOURT, T.H. NIELSEN, B. HELly et al., « Thessalia and Adjacents Regions ", in M.H. HANSEN, T.H. NIELSEN (éd.), An Inventory of Archaic and Classical Poleis, Oxford, 2004, p. 676-731.

J.-C. DECOURT, A. TZIAFALIAS, « Un nouveau règlement religieux de la région de Larissa », in Proceedings of the $3^{\text {rd }}$ Archaeological Meeting of Thessaly and Central Greece [AETHSE] III, Volos, 2012, p. 463-473.

J.-C. DECOURT, A. TZIAfALIAS, « Dieux et héros à Pythion : quelques particularités », in Proceedings of the $4^{\text {th }}$ Archaeological Meeting of Thessaly and Central Greece [AETHSE] IV, Volos, sous presse.

N. DESHOURS, Les mystères d'Andania. Étude d'épigraphie et d'histoire religieuse, Bordeaux, 2006.

M. DETIENNE, Les jardins d'Adonis. La mythologie des aromates en Grèce, Paris, 1972.

G. DOWNEY, Antioch-on-the-Orontes III 1937-1939, Princeton, 1941. 
S. EITREM, s.v. « Moirai », RE XV (1932), col. 2449-2497.

M. FRAENKEL, Die Inschriften von Pergamon, Berlin, 1890-1895.

M. ERRINGTON, s.v. « Bolbe », Brill's NP II (2003), col. 714.

M.-L. FREYBURGER-GALLAND, G. FREYBURGER, J.-Chr. TAUTIL, Sectes religieuses en Grèce et à Rome dans l'Antiquité païenne, Paris, 1998, p. 101-104.

J. GAGÉ, Apollon Romain. Essai sur le culte d'Apollon et le développement du ritus Graecus à Rome : des origines à Auguste, Paris, 1955.

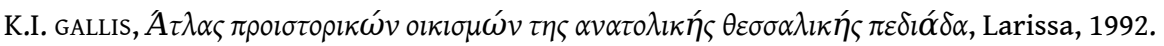

J.L. GARCIA RAMON, « Onomastique grecque, dialectes grecs et grammaire comparée », in C. DOBIASLALOU (éd.), Des dialectes grecs aux Lois de Gortyne, Paris, 1999, p. 7-22.

R. GARLAND, Introducing New Gods. The Politics of Athenian Religion, Londres, 1992, p. 111-114.

L. GAWLINSKI, The Sacred Law of Andania: a New Text with Commentary, Berlin / Boston, 2012.

R. GINOUVÈs, Dictionnaire méthodique de l'architecture grecque et romaine III, Paris, 1998.

Z. GOCEVA, D. POPOV, s.v. « Bendis », LIMC III (1986), p. 95-97.

F. GRAF, « Lesser Mysteries - not Less Mysterious », in M.B. cosmopoulos (éd.), Greek Mysteries. The Archaeology and Ritual of Ancient Greek Secret Cults, Londres, 2003a, p. 241-262.

F. GRAF, s.v. « Artemis », Brill's NP II (2003b), col. 63-64.

D. GRANINGER, Cult and Koinon in Hellenistic Thessaly, Leyde, 2011.

E. DE HALÁCSY, Conspectus Florae Graecae, Leipzig, 1908, I, p. 312-313.

M. HAtzopoulos, Cultes et rites de passage en Macédoine, Athènes / Paris, 1994.

A. HENRICHS, s.v. « Moira », Brill's NP IX (2006), col. 124-126.

M. HEINZ, Thessalische Weihreliefs, 1998, thèse en ligne, http://www-brs.ub.ruhr-uni-bochum.de/ netahtml/HSS/Diss/HeinzMargarete/diss.pdf.

M.-C. HELLMANN, Recherches sur le vocabulaire de l'architecture grecque d'après les inscriptions de Délos, Paris, 1993.

B. HELLY, « À Larisa. Bouleversement et remise en ordre des sanctuaires », Mnemosyne 23 (1973),

p. 250-296.

B. HELly, L'État thessalien, Aleuas le Roux, les tétrades et les tagoi, Lyon, 1995.

B. HELLY, « Gloses thessaliennes et realia », in G. ROCCA (éd.), Dialetti, dialettismi, generi letterari e funzioni sociali, Alessandria, 2004, p. 266-280.

B. HELLY « Consécration d'un enclos funéraire à Ennodia Ilias à Larisa (Thessalie) », Kernos 23 (2010), p. 53-65.

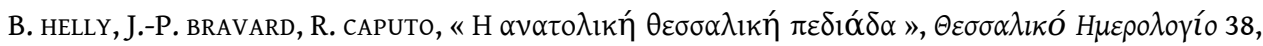
p. 3-35; 39 (2001), p. 73-96; 40 (2002), p. 145-164; 41 (2003), p. 165-190.

B. HELLY, J.L. GARCIA RAMON, « Ennodia Koroutarra ("celle qui dote de nourriture, de croissance”) et autres divinités kourotrophes en Thessalie », in A. BLANC, L. DUBOIS (éd.), Polymétis. Mélanges en l'honneur de Françoise Bader, Liège, 2013.

P. HERRMANN, Ergebnisse einer Reise in Nordostlydien, Vienne, 1962. 
P. HERRMANN, H. MALAY, New documents from Lydia, Vienne, 2007 (TAM Suppl. 24).

C. HUDE, Corpus Medicorum Graecorum II. Aretaeus, Berlin, 1958.

B. IntZesiloglou, «The Archaic Temple of Apollo at Ancient Metropolis (Thessaly) », in M. Stamatopoulou, M. Yeroulanou (éd.), Excavating Classical Culture. Recents Archaeological Discoveries in Greece, Oxford, 2002, p. 109-115.

H. JeAnMaIRE, Dionysos. Histoire du culte de Bacchus, Paris, 1951.

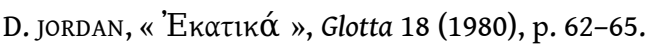

F. JUSTI, Iranisches Namenbuch, Marburg, 1890.

M. JOST « Mystery Cults in Arcadia », in M.B. COMPULSE (éd.), Greek Mysteries. The Archaeology and Ritual of Ancient Greek Secret Cults, Londres, 2002.

R. KASSEL, C. AUSTIN, Poetae Comici Graeci V, Berlin / New York, 1986.

E. KEARNS, Greek Cult Practice from Epigraphical Evidence, Uppsala, 1995, p. 65-70.

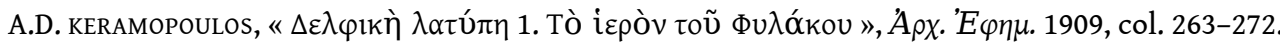

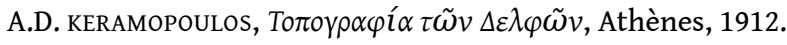

T. коск, Comicorum Graecorum Fragmenta II, Leipzig, 1884.

D. KNOEPFLER, « Du nouveau sur les dèmes et tribus d'Érétrie », REG 108 (1998), p. XXXV-XL.

G. LABARRE « Les origines et la diffusion du culte de Mên », in H. BRU, F. KIRBILHER, S. LEBRETON (éd.), L'Asie Mineure dans l'Antiquité. Échanges, populations et territoires, Rennes, 2009, p. 389-414.

E. LANE, Corpus Monumentorum Religionis Dei Menis, Leyde, 1971-1978 (EPRO 19).

J.L. LightFoot, Lucian. On the Syrian Goddess, Oxford, 2003.

H. LOHMANN, s.v. « Brauron », Brill's NP II (2003), col. 753-754.

E. LUPU, Greek Sacred Law. A Collection of New Documents (NGSL), Leyde / Boston, 2009 [2005].

H. MALAY, Greek and Latin Inscriptions in the Manisa Museum, Vienne, 1994.

A. MARCHIORI, I Deipnosofisti, Rome, 2001.

V. MEHL, « Parfums de fêtes. Usage de parfums et sacrifices sanglants », in P. BRULÉ (éd.), Le sacrifice antique. Vestiges, procédures et stratégies, Rennes, 2008, p. 167-186.

M. MILI, Religion and Society in Ancient Thessaly, Oxford, 2014.

L. MOULINIER, Le pur et l'impur dans la pensée des Grecs d'Homère à Aristote, Paris, 1952.

A. MOUSTAKA, Kulte und Mythen auf thessalischen Münzen, Würzburg, 1983.

J.C. NIEUWLAND, H.S. VERSNEL, « Een Kleinaziatisch Staphorst : de religieuze cultuur van beichtinscripties » Lampas 23 (1990), p. 165-186.

E. OBERHUMMER, s.v. « Bolbe », RE III (1897), col. 668-669.

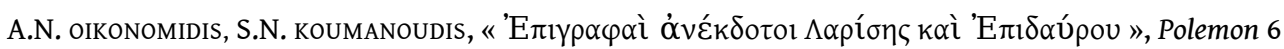
(1956-1957), p. 17-32.

A.K. ORLANDOS, I.N. TRAVLOS, $\Lambda \varepsilon \xi ı \kappa o ́ v ~ \alpha \rho \chi \alpha i ́ \omega v ~ \alpha \rho \chi \imath \tau \varepsilon \kappa \tau o v ı \kappa \omega ́ v ~ o ́ \rho \omega v$, Athènes, 1986.

J. PAPADIMITRIOU, « Le sanctuaire d'Apollon Maléatas à Épidaure », BCH 73 (1949), p. 361-383. 
R. PARKER, Miasma, Pollution and Purification in Early Greek Religion, Oxford, 1983.

R. PARKER, Polytheism and Society at Athens, Oxford, 2005.

A.B. Petropoulou, « Prothysis and Altar : a Case Study », in R. ÉTIEnNe, M.-Th. Le DinAhEt (éd.), L'espace sacrificiel dans les civilisations méditerranéennes de l'Antiquité, Lyon, 1991, p. 25-31.

M.Z. PETROPOULOU, Animal Sacrifice in Ancient Greek Religion, Judaïsm and Christianity, 100 BC-AD 200, Oxford, 2008.

G. PETZL, Die Inschriften von Smyrna, Bonn, 1987 (IK 24).

G. PETZL, H. MALAY, «A New Confession Inscription from the Katakekaumene », GRBS 28 (1987), p. $459-472$.

V. PIRENNE-DELFORGE, G. PIRONTI, « Les Moires entre la naissance et la mort : de la représentation au culte », Études de lettres (2011), p. 93-113.

D. POPOV, «Essence, origine et propagation du culte de la déesse thrace Bendis », DHA 21 (1976), p. 289-303.

C. PlaneauX, « The Date of Bendis' Entry into Attica », CJ 96.2 (2011), p. 165-192.

F. DE POLIGNAC, « Entre privé, public, civique : à propos de l'intégration de cultes extérieurs dans l'Athènes classique ", in B. LEGRAS, G. THÜR (éd.), Symposium 2011. Études de droit hellénistique, Vienne, 2012, p. 199-210.

K. PREISENDANZ, Papyri Graecae Magicae, Munich, 2001.

W.K. PRentice, in E. LitTMAnN, D. MAgie, D.R. StUART, Syria. Publications of the Princeton University Archaeological Expeditions to Syria in 1904-1905 and 1909, Section B, Northern Syria, Leyde, 1922.

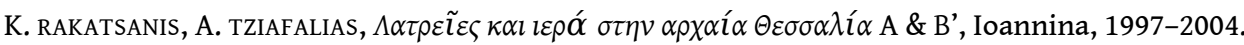

O. REUTHER, s.v. « Tympanum », RE VIIIA (1948), col. 1749-1754.

G. ROUGEMONT, Lois sacrées et règlements religieux, Athènes, 1977 (CID I).

M. SEGRE, G. PUGLIESE CARRATELLI, « Tituli Camirenses », ASAtene 27-29 (1949-1951), p. 141-318.

M. SEGRE, Iscrizioni di Cos 1, Rome, 1993.

J. SCHEID, « Graeco ritu : A Typically Roman Way of Honoring the Gods », HSCP 97 (1995), p. 15-31.

J. SCHEID, « Nouveau rite et nouvelle piété. Réflexions sur le ritus Graecus », in Ansichten griechischer Rituale. Geburstags-Symposium für Walter Burkert, Stuttgart / Leipzig, 1998, p. 168-182.

F. SOKOLOWSKI, Lois sacrées de l'Asie Mineure, Paris, 1955.

F. SокоLоWSKI, Lois sacrées des cités grecques. Supplément, Paris, 1962.

F. SOKоLOWSKI, Lois sacrées des cités grecques, Paris, 1969.

G. SUSINI, « Iscrizioni greche di Megiste e della Licia nel museo di Mitilene », ASAA NS 14-16

(1952-1954), p. 341-350.

L. TEILLIER, Artémis à l'épreuve de la chèvre : de l'éthologie aux pratiques militaires, Mémoire de Master 2, Montpellier, 2011.

J. TEIXIDOR, s.v. « Anaeitis », LIMC I (1981), p. 754-756. 


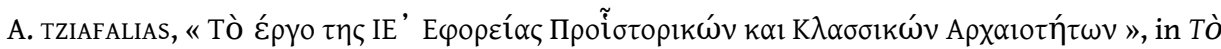
E

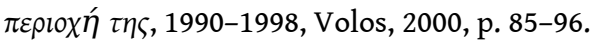

A. tZiafalias, L. DARmezin, J.-C. Decourt, B. helly, G. LuCAS, Inscriptions d'Atrax en Pélasgiotide (Thessalie), Paris / Athènes, sous presse.

E. VANDERPOOL, « News Letter from Greece », AJA 60 (1956), p. 267.

J.G. VINOGRADOV, « The Inscribed Bronze Plate from Vani », VDI 313.3 (1995), p. 48-70 [en russe, résumé en anglais].

K. WENDEL, Scholia in Theocritum vetera, Leipzig, 1914.

J.-B. YON, « Coiffeurs et barbiers dans les sanctuaires du Proche-Orient », Tempora 18 (2007-2008), p. 81-94.

\section{NOTES}

1. Quelques indications bibliographiques importantes: HEINZ (1998); RAKATSANIS, TZIAFALIAS (1997-2004) ; GRANINGER (2011) ; MILI (2014), paru après la rédaction de cet article.

2. INTZESILOGLOU (2002).

3. TZIAFALIAS (2000) ; DECOURT, NIELSEN, HELly (2004), p. 726-727, no 669.

4. TZIAFALIAS et al. (sous presse).

5. DeCourt, tZiAfalias (sous presse). Le corpus de la Tripolis de Perrhébie est en préparation à Lyon.

6. BOUCHON, HELLY (2013) ; BOUCHON, TZIAFALIAS (2014).

7. Synthèse et bibliographie des découvertes, du Néolithique récent à l'Époque géométrique, GALLIS (1992), p. 145-146.

8. Dans l'édition qui suit, je me conforme bien entendu à l'usage dans l'emploi des lettres pointées ; lorsque la lecture me paraît trop peu assurée, je la fais suivre par (?).

9. SоKоLOWSKI (1955); sоKоLOWSKI (1962); sоKоLOWSKI (1969); LUPU (2009); pour une réflexion méthodologique sur ce recueil en préparation, CARBON, PIRENNE-DELFORGE (2012) ; CARBON (2012).

10. Pour ces questions de vocabulaire architectural, ORLANDOS, TRAVLOS (1986), HELLMANN (1993),

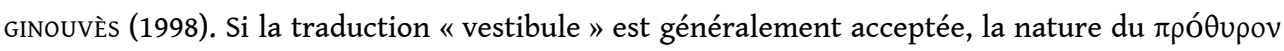
semble faire discussion entre les spécialistes. Pour GINOUvÈs, p. 157, il s'agit «d'une pièce largement ouverte sur l'extérieur, mais comprise dans la ligne de façade »; pour HELLMANN, p. 348, " on l'imagine en avancée par rapport à la porte ", mais elle admet aussi, en se fondant sur Platon, Prot., 314c3, qu'« il pourrait s'agir d'un vestibule d'entrée ouvert sur la rue, la porte d'entrée étant placée en retrait ", sans débordement sur la voie.

11. HELLMANN (1993), p. 334.

12. Une restitution semblable est proposée pour une inscription lacunaire d'Épidaure, IG IV 2, 1,

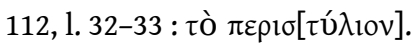

13. Cette duplication Artémis / Artémis Phylakè et Moire / Moire+Hélios est-elle liée au caractère double, grec et non grec, du culte célébré dans le sanctuaire? On la retrouve en tous cas apparemment aussi pour certaines divinités « orientales », comme Adara et Lilla, Allaia et Lillaia. 14. Pour le premier sens chez Vitruve, voir III, 5, 12, IV, 3, 6 et IV, 7, 5; pour le second, IV, 6, 4. Sur ces questions, voir GINOUVÈs (1998), p. 129, et HELLMANN (1993), p. 32 ; REUTHER (1948) liste l'ensemble des sens du mot. 
15. GINOUVÈs (1998), p. 18, y voit « une surface plus ou moins précisément définie (...) et normalement consacrée à un usage particulier » et, p. 171, plus étroitement, « une surface dallée (...) servant à battre les céréales »; p. 186, il évoque "une place plus ou moins arrondie où pouvaient se dérouler des danses ou se célébrer un drame sacré », en référence à l'aire qui se trouvait devant les portiques des Athéniens à Delphes (BOMMELAER [1991], p. 146). Sur ö $\lambda \omega \varsigma$, voir aussi HELLY (2004), p. 266-280.

16. IG XII 9, 189 ; SOKOLOWSKI (1969), 93, 5 ; KNOEPFLER (1998).

17. Scholia in Theocritum (scholia vetera) prolegomenon anecdote poem 2, v. 66 11/12c (éd. WENDEL), kaì

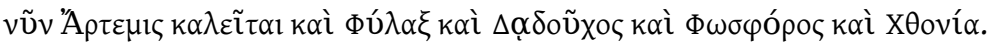

18. Hésychius 969.

19. Anthologie Palatine VI, $157,1$.

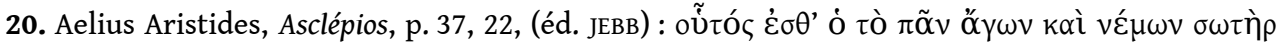

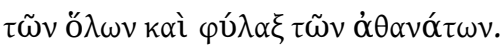

21. Amorgos : IG XII 7, 419. Smyrne : PETZL (1987), 770 et 771. Pergame : FRAENKEL (1890-1895), I, 183. Rome : IG XIV, 1000 II, IGUR, 195. On pourrait y ajouter, chez Hésiode, les hommes de la race d'or (Travaux, 123) et des Immortels innombrables, mais anonymes (Travaux, 253), qui sont qualifiés de $\varphi \hat{\jmath} \lambda \alpha \kappa \varepsilon \zeta \theta v \eta \tau \tilde{\omega} v \dot{\alpha} v \theta \rho \omega ́ \pi \omega v$.

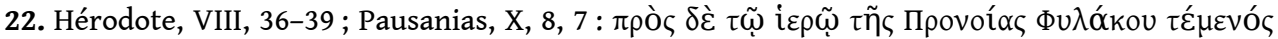

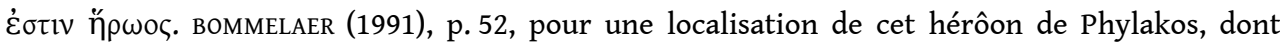
KÉRAMOPOULOS (1909), p. 266, et (1912), p. 55, suggérait, mais sans preuve, qu'une partie était réservée à Artémis.

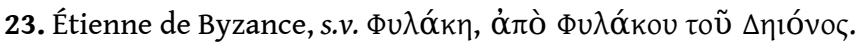

24. IG IX 2, 573, et ARVANITOPoulos (1911), p. 123-124, $\mathrm{n}^{\circ} 1$ : ces deux dédicaces sont faites à Déméter Phylakè et à Dionysos Karpios ; OIKONOMIDIS, KOUMANOUDIS (1956-1957), p. 17-22, no 1.

25. Sur ce dieu, synthèse dans LABARRE (2009), avec mise à jour bibliographique.

26. LABARRE (2009), p. 393, note 23.

27. LANE (1971-1978), II, 3, Nisa 41.

28. NIEUWLAN, VeRSNel (1990); SEG 40, 1711. Pour l'assimilation à Artémis : BOYCE, GRENET (1991), p. 205-253, SEG 41, 1799; MALAY (1994), no 160, SEG 44, 952 ; synthèse et bibliographie dans TEIXIDOR (1981).

29. CORSTEN (1991).

30. LANE (1976), 1, no 89.

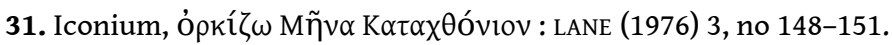

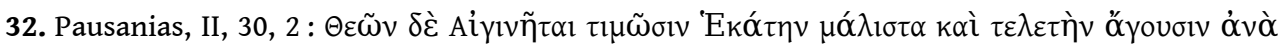

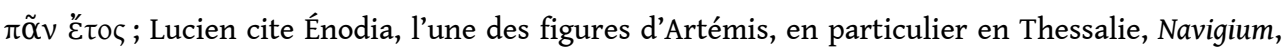

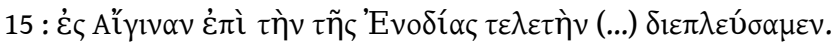

33. Pour la première interprétation : HERRMANN (1962), p. 24-26, no 18; TAM V 1, 525 ; TAM Suppl 23, 86 ; LANe (1976), p. 66, no 33, 42, 47, 86 et AI ; PETZl, MALAy (1987), p. 459-472. Pour une interprétation comme épiclèse, PETZL, MALAY (1987) ; HERRMANN, MALAY (2007), p. 75-77.

34. LABARRE (2009), p. 397-399.

35. LANE (1971), 1, no 13 (Sounion ; voir aussi SOKOLOWSKI [1969], 55) et 16-17 (Rhodes).

36. Mên peut être associé à d'autres divinités représentant les éléments, Zeus, Gê, Pan, Apollon et Hélios : voir LANE (1976), 3, p. 81-98 et la plaque de bronze de Vani, VINOGRADOV (1995), p. 48-70, SEG 45, 1876, 19. Apollon, Hélios et Pan sont présents aussi dans notre règlement.

37. eitrem (1932); DE ANGELI (1992); HENRICHS (2006); PIRENNE-DELFORGE, PIRONTI (2011). J'utilise volontairement le nom sans article : parce qu'ici Moire, au même titre qu'Artémis, a, si l'on peut dire, une "personnalité » et on ne dit pas «l'Artémis », mais surtout parce qu'il n'est pas 
impossible que, sous ce nom, se dissimule une divinité orientale hellénisée, comme pour Phylakè justement.

38. Les Moires sont filles de Zeus chez Hésiode, Théogonie, 904.

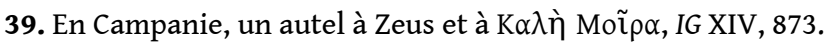

40. IG IX 2, 282. Il existe en Thessalie une autre dédicace aux Moires, déposée au Musée d'Halmyros et encore inédite.

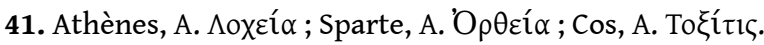

42. IG V 1, 602.

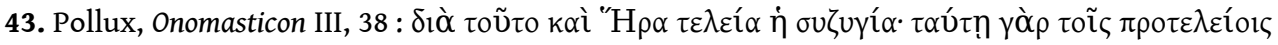

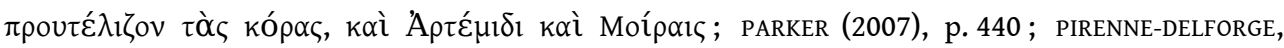
PIRONTI (2011), p. 104.

44. JORDAN (1980), p. 62-65.

45. L. 9/10. NEI I : nu et epsilon sont sûrs, on lit ensuite un bas de haste, puis, peut-être, un sigma ; $\Pi \Lambda \mathrm{HN}$ est bien lisible.

46. Pan n'est pas une divinité très présente au Proche-Orient, à la différence de l'Égypte, et son assimilation à un dieu oriental était peut-être loin d'être évidente, ce qui expliquerait la précision apportée par l'auteur de l'inscription. Par ailleurs, aucun des nombreux Pans que cite Nonnos de Panopolis dans ses Dionysiaques ne peut être rapproché des quelques lettres que nous lisons.

47. Le premier qualificatif peut être aussi celui d'Artémis, comme à Camiros : SEGRE, PUGLIESE

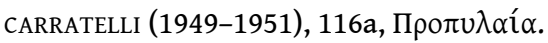

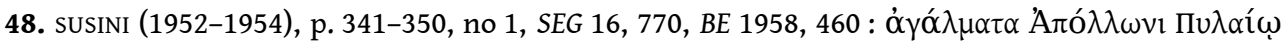

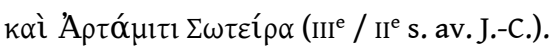

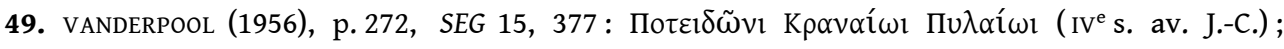
MOUSTAKA (1983), p. 22.

50. Bó $\lambda \lambda \varepsilon \varepsilon v$ est gravé deux fois, parfaitement lisible dans les deux cas, la première sans objet exprimé, la seconde suivi de ó $\tau 1$ ồ $\theta \varepsilon \lambda \tilde{\eta} ı$. Je n'ai pas trouvé de parallèle : on peut comprendre qu'il s'agit d'un mode particulier de présentation des offrandes, impliquant un mouvement vif ou brusque. On penserait à quelque chose jeté dans un bothros, mais rien dans le texte ne laisse supposer la présence d'un tel dispositif.

51. Pausanias, I, 24, 2, dans la description d'un groupe statuaire à Athènes. Je remercie V. Pirenne-Delforge d'avoir attiré mon attention sur ce passage.

52. Le monde romain connaît une opposition entre sacrifice ritu Romano et ritu Graeco (GAGÉ [1955] ; SCHEID [1995], sCHEID [1998]), distinction qui semble assez tardive (II ${ }^{\mathrm{e}}$ s. av. J.-C., SCHEID [1998], p. 18). Mais le contexte est différent : les divinités en cause peuvent être grecques (toutes les divinités grecques ne sont pas concernées), mais aussi romaines; le rituel reste romain (y compris dans le cas de la consultation des Livres Sibyllins ou de la célébration des Ludi saeculares, SCHEID [1998], p. 25-28); il est simplement modifié par des gestes grecs, mots ou attitudes (sCHEID [1998], p. 28).

53. Sur l'exclusion du porc comme victime, LUPU (2005), p. 57-58. CLINTON (2005).

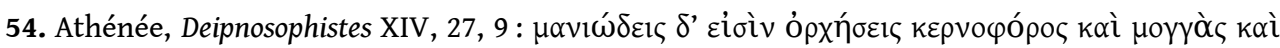
$\theta \varepsilon \rho \mu \alpha v \sigma \tau \rho i ́ c$.

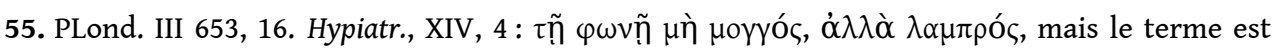
tardif (IV s. ap. J.-C.).

56. Pour les coïncidences géographiques, on peut penser à la ville de Lilaia en Phocide ou le fleuve de Bythinie (Pline, Hist. Nat. V, 149). Pour l'anthroponyme, Eschyle, Perses, 308 ; cf. JUSTI (1890), s.v.

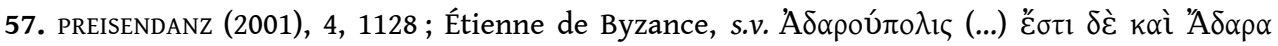

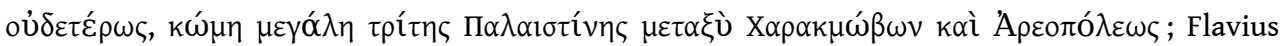




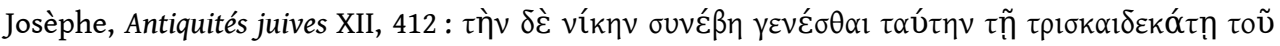

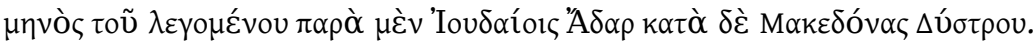

58. Infra $\S 5$.

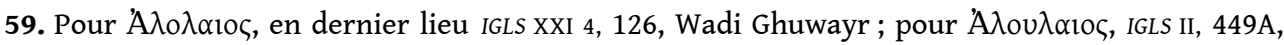
Qâtoûra, deux épitaphes. Voir aussi IGLS XIII 2, 9519.

60. PRENTICE (1922), p. 157, no 11.

61. Hésychius 587 , s.v.

62. Euripide, Hécube, 827 ; Lycophron, Alexandra, 1468.

63. Théocrite, 171, 34 ; Hésychius, 681, s.v.

64. Pour le masculin $\kappa \alpha \theta \alpha \rho \tau \eta ́$ s on connaît un témoignage épigraphique, sur une épitaphe de Sparte, IG V 1, 209.25, où un certain Andronikos est ainsi qualifié, sans qu'on puisse en savoir plus

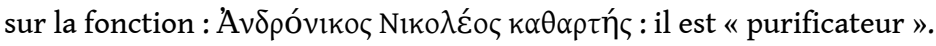

65. Sur la question générale des impuretés, PARKER (1983).

66. Tò ífó peut être compris de plusieurs façons : en B5, le mot désigne clairement des objets, objets que l'on déplace, en B18. En B8/9, il s'agit soit des offrandes que l'impétrant présente, soit encore d'objets mobiliers, soit enfin des lieux eux-mêmes que le non-initié risque de souiller : j'ai conservé ici le terme grec faute de pouvoir trancher.

67. Les durées connues par d'autres inscriptions sont extrêmement variées, de quelques heures (à condition, souvent, de procéder à une ablution totale ou à une douche rituelles) à plusieurs semaines : PARKER (1983), p. 48-52.

68. GRAF (2003), p. 2, insiste sur le rôle majeur de l'hydrophore dans les mystères d'Artémis à Didyme, mystères dont on ne connaît pas le fonctionnement exact ; sur l'usage de l'eau, voir PARKER (1983), p. 19-22 et 226-227.

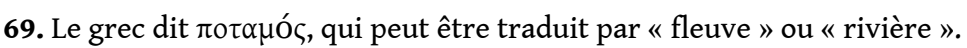

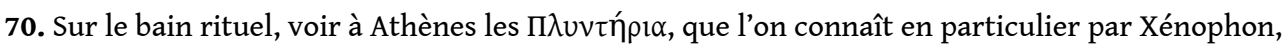
Helléniques I, 4, 12 : le bain se faisait dans la mer : voir PARKER (2005), p. 226 et 478.

71. Pour ces épiclèses, voir surtout Pausanias, II, 7, 6 ; III, 23, 10 ; IV , 4, 2 ; V, 14, 6 ; VIII, 2, 22, et Strabon, 343 et 350 .

72. JоSт (2002), p. 147, remarque que, en Arcadie au moins, la localisation des sanctuaires peut varier : dans la cité, sur ses marges proches ou dans des zones à l'écart, en particulier près de marécages ou de sources.

73. Strabon, IX, $5,2$.

74. Apollonios de Rhodes, Argonautiques I, 596 et IV, 617. Une cité homonyme est mentionnée par Strabon, IX, 5, 22, qui cite un fragment d'Hésiode. Sur la question, très complexe, du réseau hydrographique dans la plaine orientale et des lacs de la région, voir HELLY, BRAVARD, CAPUTO (2000-2003).

75. Sanctuaire simplement hors les murs ou sanctuaire de confins? Impossible de trancher dans la mesure où le lieu d'érection de la stèle et donc l'emplacement du sanctuaire sont inconnus. J'ai suggéré (DECOURT [2012], p. 468) une localisation aux confins des territoires de Larissa et Sykourion, mais cela reste une hypothèse.

76. CASABONA (1966).

77. Diphilos, 42,10 [éd. KASSEL, AUSTIN (1986)], repris par Athénée, VII, 39, 12, l'utilise avec घủXńv

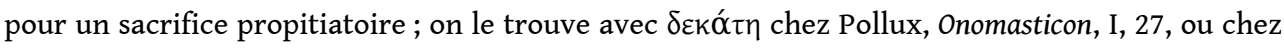

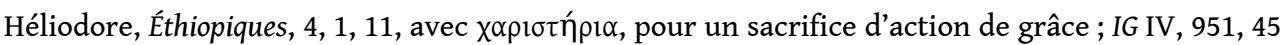
(Épidaure).

78. Dans la littérature, le verbe est d'emploi poétique : Eschyle, Agamemnon, 1503-1504; Euripide, Oreste, 562 ; Homère, Hymne à Apollon, 491, et la nuance temporelle n'apparaît pas vraiment ; Aristophane, Ploutos, 1116 (avec $\lambda_{\imath} \beta \alpha v \omega \tau$ tóv comme complément, avec une valeur plutôt locative pour le préfixe : «faire brûler sur [l'autel] l'encens »), ou d'emploi tardif. L'emploi épigraphique 


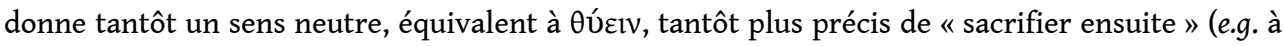
Cos, sокоLоwsкi [1969], 151A, $20 ; 157 \mathrm{~A}, 3)$.

79. Platon, Cratyle, 401d ; les autres sens « sacrifier pour, à la place de quelqu'un » et « sacrifier pour, en faveur de quelqu'un » ne conviennent pas, d'après le contexte. Cf. PETROPOuLOu (1991), p. 25-31. Dans le cas présent, étant donné la place du verbe, on doit comprendre ce sacrifice dans le sens de sacrifice qui en précède un (ou plusieurs) autre et non comme un sacrifice préalable aux cérémonies d'initiation : sur ce point précis, voir LUPU (2005), p. 59-60.

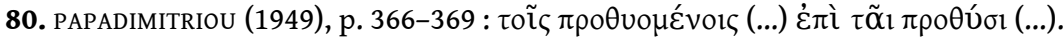

81. ROUGEMONT (1977), no 3.

82. CASABONA (1966), p. 102.

83. C'est le sens proposé par Homolle pour l'inscription de Delphes. Les autres significations suggérées par différents savants, sacrifier autrement, sans utiliser le vin (Kéramopoulos, Sokolowski), faire une autre offrande à la place du vin dérobé (Buck), toutes résumées par Rougemont, ne conviennent pas.

84. Sur l'holocauste du coq par des mystes à Déméter, Porphyre, De Abstinentia IV, 16.

85. TEILLIER (2011). Voir par exemple, à Marathon, le sacrifice à Artémis de cinq cents chèvres annuellement, signalé par Hérodote, VI, 117 et Xénophon, Anabase III, 2, 12.

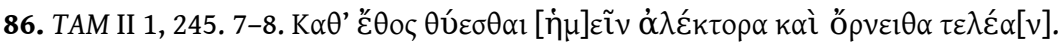

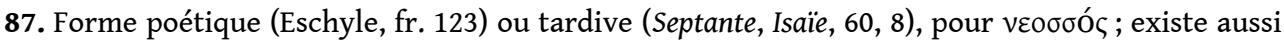

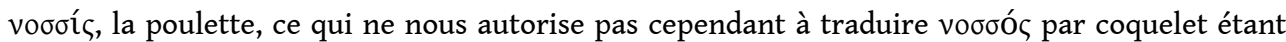

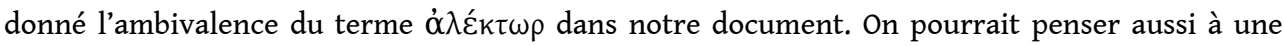
coquille, avec l'omission de l'epsilon, mais la qualité de la gravure rend l'hypothèse fragile. La Souda 208 y reconnait le moineau, ce qui ne convient pas ici.

88. L'élevage d'oies dans les sanctuaires est attesté, par exemple par Artémidore, Oneir., $64.25 \mathrm{H}$ :

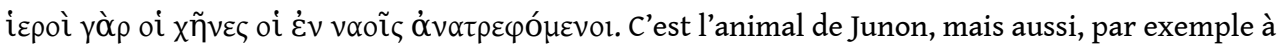
Chypre, d'Aphrodite.

89. D'ARCY THOMPSON (1936), p. 290. Le nom lui-même n'est pas assuré, puisqu'il n'apparaît que dans quelques manuscrits d'Aristote, HistAn, 593b5; sur les autres il est nommé $\pi u ́ \gamma \alpha \rho \gamma o \varsigma$ (ibid.

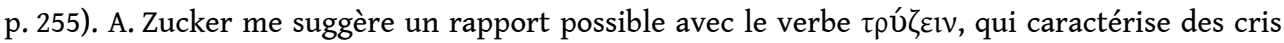

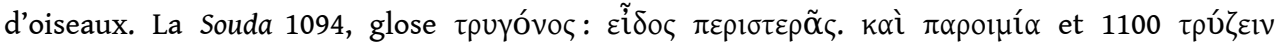

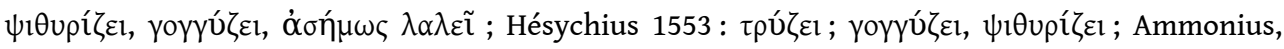

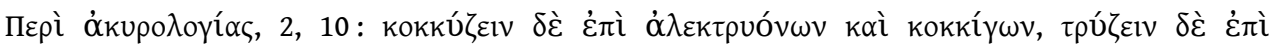
$\tau \rho u \gamma o ́ v \omega v$.

90. D’ARCY THOMPSON (1947). Sur les poissons dans le culte d'Artémis : BODSON (1978), p. 49.

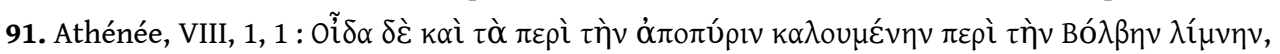

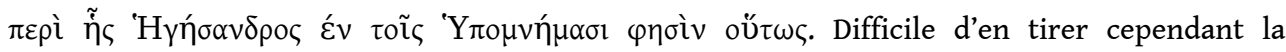
conclusion que ce terme ne désignait qu'une ou plusieurs sortes de poissons exclusivement d'eau douce. Ailleurs (311a) en effet, Athénée rapproche la qualité gustative de l'óđo

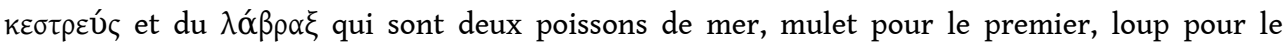

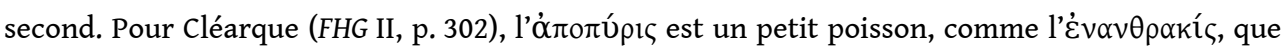
l'on grille de la même façon. Le Bolbè cité par Athénée est un lac marécageux de Mygdonie ( OBERHUMMER [1897]; ERRINGTON [2003]). Étienne de Byzance, s.v. Bó $\beta \alpha$ l, mentionne une ville de ce

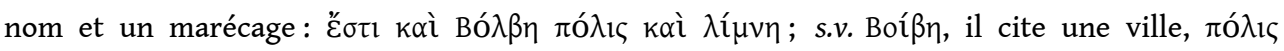

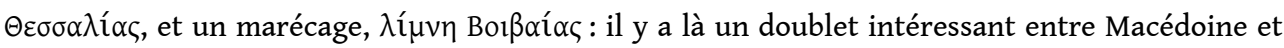
Thessalie, comme il en est bien d'autres.

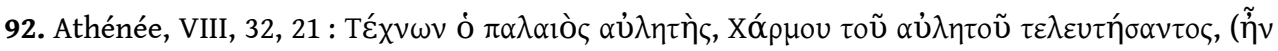

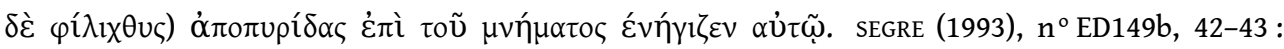

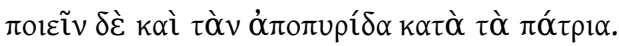




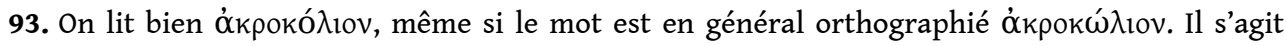
clairement d'un organe ou d'un membre double. Le rédacteur a sans doute confondu deux

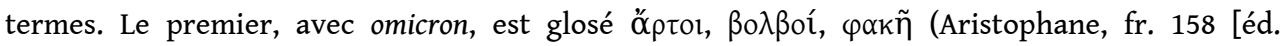
EDMONDS]), qui ne convient évidemment pas ici; le second, avec oméga, désigne "les parties extrêmes ou intérieures d'un animal (museau, groin, oreilles, pieds, boyaux) »; la traduction choisie, « pieds » l'a été par rapprochement avec le terme culinaire « pieds de porc ».

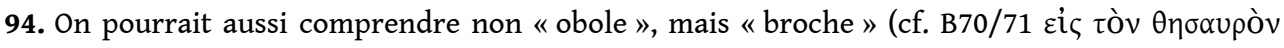

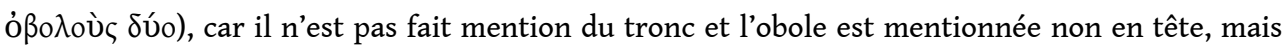

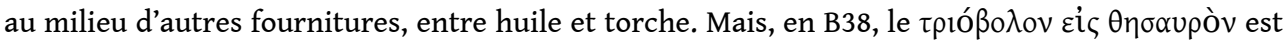
aussi placé au milieu de fournitures ou offrandes, bouillie et beignet avant, huile et vin après.

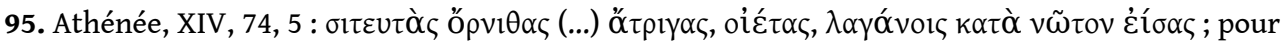
l'identification, voir MARCHIORI (2001), p. 1673 note 6. Selon Galien, Propriétés des aliments I, 4, il

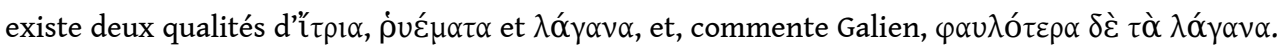
Hésychius, s.v.

96. KEARNS (1995).

97. DOWNEY (1941), p. 93, no 156 ; BE 1946, 194.

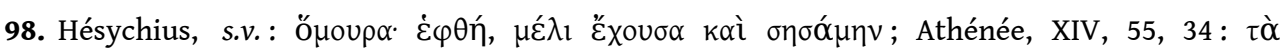

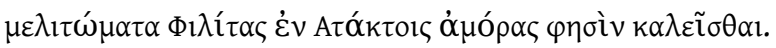

99. Sur l'encens dans le culte, BRUIT-ZAIDMAN (2008) ; DETIENNE (1972).

100. Aretas, SD 2.II (éd. HUDE [1958]).

101. Pour tout ce développement, je dois beaucoup à $S$. Amigues, que je remercie pour son aide précieuse dans un domaine qui m'est étranger ; voir AMIGUES (1995), p. 3-29. Voir aussi DETIENNE (1972), p. 177-178, qui signale l'utilisation de la rue comme poison par Médée lors de son passage à Lemnos ; ses vertus anaphrodisiaques en faisaient un produit utilisé par les mystes, d'après une scholie à Nicandre, Alexipharmaka, 410. Detienne relève que la rue était employée en cuisine par les Romains, mais pas par les Grecs. L'inscription de Marmarini ne permet pas d'aller contre cette affirmation : elle est mentionnée, sous ses deux noms, entre des offrandes cuisinées (gâteaux et bouillie), et des plantes pour fumigations (encens et myrrhe) et de l'huile pour les lampes.

102. Difficile ici de savoir si le rédacteur envisage une seule sorte de rue/harmale, en dupliquant le terme, ou s'il songe à deux variétés de la même plante: pour conserver la répétition, c'est le parti qui a été retenu dans la traduction.

103. HALÁCSY (1908), p. 312-313 : «Frequens in planitie thessala a Trikala ad Larissa et Volo ».

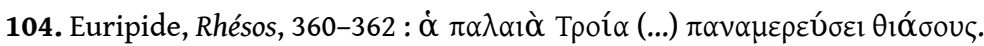

105. Pour le verbe, Diphilos, fr. 43, 3 (éd. коск [1884]) (= Athénée, VII, 39, 5). Pour le nom, e.g. IG II ${ }^{2}$, 2403 ; Ménandre, Bouclier, 232 ; Hésychius 1256, s.v.

106. Je pencherais pour cette dernière solution: les deux faces sont indépendantes l'une de l'autre.

107. BODSON (1986).

108. C'est le mot que l'on retrouve, par exemple, dans le règlement des mystères d'Andanie : DESHOURS (2006); GAWLINSKI (2012).

109. JOST (2003) ; GRAF (2003b) ; voir aussi GRAF (2003a).

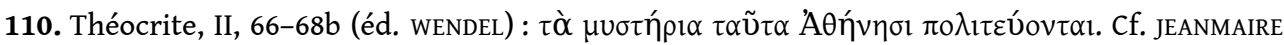
(1951), p. 261.

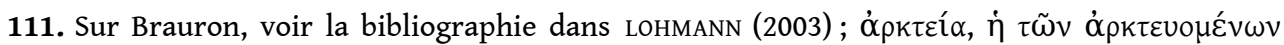

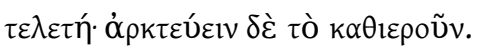

112. Sur cette question YON (2007-2008).

113. Lucien, De Dea Syria, 55 ; voir LIGHTFOOT (2003), p. 517.

114. L. 27, la forme i $\lambda \alpha \tau \eta \rho i ́ \alpha \varsigma$ est nouvelle. Sans sigma, on ne connaît qu'une forme tardive (

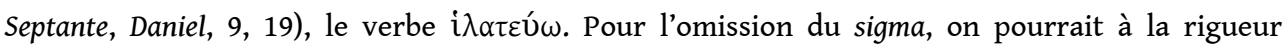


supposer une erreur de gravure, mais le changement de genre et la construction posent problème. 'I $\lambda \alpha \sigma \tau \eta ́ p ı v$ qui figure dans la Chronique de Lindos B49n, mais aussi sur une dédicace à

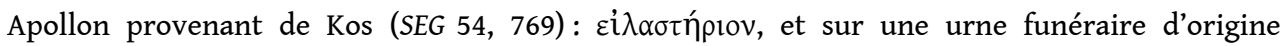
inconnue du Louvre $(S E G 9,910)$ : ì $\alpha \sigma \tau \eta ́ p ı v$, avec le sens d'offrande expiatoire ou propiatoire ; il a le même sens dans une scholie à Apollonios de Rhodes (Scholia in Apollonii Rhodii Argonautica

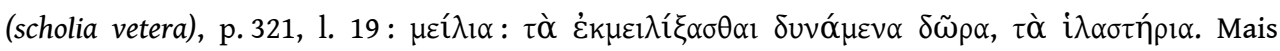

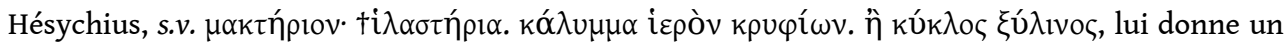
tout autre sens. Ici, il s'agirait de donner une obole comme offrande expiatoire au fait de ne pas s'être rasé.

115. L'existence d'une seconde stèle à gauche de la première est admise dans le cas du règlement des mystères d'Andanie : DESHOURS (2006), p. 55-56, qui s'appuie sur des indices internes au texte conservé, et GAWLINSKI (2012), p. 61.

116. Sur le culte de Bendis et les modalités de son entrée à Athènes, voir GOCEVA, POPOV (1976) ; PLANEAUX (2001); GARLAND, (1992), p. 111-114 ; FREYBURGER-GALLAND, FREYBURGER, TAUTIL (1998), p. 101-104; AUFFARTH (2003).

117. SOKOLOWSKI (1969), no 55.

118. Sur la question des différents statuts des cultes " étrangers » ou « importés ", privé, public, civique, sur le passage de l'un à l'autre, voir DE POLIGNAC (2012) à propos de l'introduction du culte d'Asclépios à Athènes - les fêtes des Épidauria manifestant clairement son caractère étranger, celles, plus tardives, des Asclépieia son intégration à la vie civique. Le culte d'Artémis Phylakè appartient clairement à la première catégorie.

\section{RÉSUMÉS}

Une haute stèle de marbre opisthographe trouvée il y a quelques années à Marmarini, au nordest de Larissa (Thessalie), propose un long texte de 54 et 82 lignes aujourd'hui lisibles. En s'appuyant sur cette inscription du milieu du $\mathrm{II}^{\mathrm{e}} \mathrm{s}$. av. J.-C., qui d'une part comporte un calendrier cultuel et de l'autre un certain nombre de prescriptions touchant aux rites, le présent article propose une présentation de l'aspect probable du sanctuaire (péribole, temple, autel etc.), une liste des divinités concernées - Artémis Phylakè comme divinité principale, mais d'autres divinités grecques et surtout plusieurs divinités d'origine orientale jusqu'alors inconnues - et des remarques sur les modalités d'un culte qui était sans doute un culte à mystères. Ce document, par son contenu, par les détails qu'il donne, est une trouvaille exceptionnelle en Thessalie.

A tall opisthographic marble stela found a few years ago at Marmarini, some kilometers northeast of Larissa, Thessaly, reveals a long inscription dating to the mid-second century BC, of which only 54 and 82 lines are legible today. Discussing the two faces of the inscription, one containing a religious calendar, the other a series of ritual prescriptions, the present paper provides an overview of the probable appearance of the sanctuary (peribolos / precint, temple, altars and equipment), a list of the deities worshipped - Artemis Phylake was the main goddess, but, alongside other Greek gods and goddesses, one also finds several deities of Eastern origin, which were previously unknown - and it also provides remarks on cult performance, which very probably included rites of initiation. This inscription, due to its length and its content, is unique in Thessaly. 


\section{AUTEURS}

\section{JEAN-CLAUDE DECOURT}

UMR 5189 HiSoMA

Maison de l'Orient et de la Méditerranée Jean-Pouilloux, Lyon

Jean-claude.decourt@mom.fr

\section{A. TZIAPHALIAS}

Epitropi A Archaiou Theatrou

Mitropoli Arseniou 10

GR - 42100 Larissa

Ancienttheaterlarisas@gmail.com 